OPEN ACCESS

Edited by:

Hubert Vaudry,

Université de Rouen,

France

Reviewed by:

Philippe Valet,

Institut National de la Santé et de la

Recherche Médicale (INSERM),

France

Taka-aki Koshimizu,

Jichi Medical University, Japan

*Correspondence:

Catherine Llorens-Cortes

c.llorens-cortes@college-de-france.fr

Specialty section:

This article was submitted to

Neuroendocrine Science,

a section of the journal

Frontiers in Endocrinology

Received: 02 July 2021 Accepted: 19 October 2021

Published: 22 November 2021

Citation:

Girault-Sotias P-E, Gerbier R,

Flahault $A$, de Mota $N$ and Llorens-Cortes C (2021) Apelin and

Vasopressin: The Yin and Yang of Water Balance.

Front. Endocrinol. 12:735515. doi: 10.3389/fendo.2021.735515

\section{Apelin and Vasopressin: The Yin and Yang of Water Balance}

\author{
Pierre-Emmanuel Girault-Sotias, Romain Gerbier, Adrien Flahault, Nadia de Mota \\ and Catherine Llorens-Cortes*
}

Laboratory of Central Neuropeptides in the Regulation of Body Fluid Homeostasis and Cardiovascular Functions, Center for Interdisciplinary Research in Biology (CIRB), French National Institute for Health and Medical Research (INSERM), Unit U1050, National Center for Scientific Research (CNRS), Mixed Research Unit 7241, College de France, Paris, France

Apelin, a (neuro)vasoactive peptide, plays a prominent role in controlling body fluid homeostasis and cardiovascular functions. Experimental data performed in rodents have shown that apelin has an aquaretic effect via its central and renal actions. In the brain, apelin inhibits the phasic electrical activity of vasopressinergic neurons and the release of vasopressin from the posterior pituitary into the bloodstream and in the kidney, apelin regulates renal microcirculation and counteracts in the collecting duct, the antidiuretic effect of vasopressin occurring via the vasopressin receptor type 2 . In humans and rodents, if plasma osmolality is increased by hypertonic saline infusion/ water deprivation or decreased by water loading, plasma vasopressin and apelin are conversely regulated to maintain body fluid homeostasis. In patients with the syndrome of inappropriate antidiuresis, in which vasopressin hypersecretion leads to hyponatremia, the balance between apelin and vasopressin is significantly altered. In order to re-establish the correct balance, a metabolically stable apelin-17 analog, LIT01-196, was developed, to overcome the problem of the very short half-life (in the minute range) of apelin in vivo. In a rat experimental model of vasopressin-induced hyponatremia, subcutaneously (s.c.) administered LIT01-196 blocks the antidiuretic effect of vasopressin and the vasopressininduced increase in urinary osmolality, and induces a progressive improvement in hyponatremia, suggesting that apelin receptor activation constitutes an original approach for hyponatremia treatment.

Keywords: apelin, vasopressin, apelin receptor, metabolically stable apelin-17 analogs, diuresis, osmolality, hyponatremia

\section{DISCOVERY}

The apelin story began in 1993 with the cloning of a cDNA for an orphan receptor, given the name "APJ receptor" (putative receptor protein related to the type 1 (AT1) angiotensin receptor) from a human genomic library (1). This seven-transmembrane domain G-protein coupled receptor (GPCR) displays 31\% amino-acid (aa) sequence identity to the human AT1 receptor and is encoded by a gene on chromosome 11. However, it does not bind radiolabeled angiotensin II (Ang II) (1), and stimulation of the rat APJ receptor by Ang II does not modify cyclic adenosine monophosphate (cAMP) production, demonstrating that it is not an angiotensin receptor subtype (2). The gene encoding the APJ receptor has no introns in human and rodents (2-4). The human 
and the rat APJ receptors are 380 and 377 aa long, respectively. The APJ receptor aa sequence is conserved across species, with more than $90 \%$ sequence identity between human and rodents, and up to $50 \%$ sequence identity with other non-mammalian species, such as zebrafish and frog (2-5).

In 1998, the endogenous ligand of the orphan APJ receptor was isolated from bovine stomach tissue extracts (6). This 36-aa peptide was called apelin for APJ Endogenous LIgaNd, and the APJ receptor was renamed the apelin receptor (ApelinR).

\section{SYNTHESIS AND METABOLISM OF APELIN}

\subsection{Processing of Preproapelin}

Apelin is generated from a 77-aa precursor, preproapelin (Figure 1). The human apelin gene contains three exons, with the coding region spanning exons 1 and 2. The 3' untranslated region also spans two exons (2 and 3) (8). This structure may account for the presence of transcripts of two different sizes $(\approx 3$ $\mathrm{kb}$ and $\approx 3.6 \mathrm{~kb}$ ) in various tissues $(3,8)$. Alignment of the preproapelin aa sequences from cattle, humans, rats, and mice revealed strict conservation of the C-terminal 17 aa (aa 61 to 77 of the preproapelin sequence), known as apelin-17 or $\mathrm{K} 17 \mathrm{~F}$ (Figure 1). Various molecular forms of apelin, differing only in length, are present in vivo $(36,17$, or 13 aa at the C-terminal part of preproapelin) commonly called apelin-36, apelin-17, and apelin-13. Apelin-13 is naturally pyroglutamylated at its $\mathrm{N}$ terminus (pyroglutamyl form of apelin-13 or pE13F) (4, 912) (Figure 1).

Pairs of basic residues are present within the cattle, human, rat, and mouse preproapelin sequences, leading to the suggestion that prohormone convertases are responsible for processing the precursor to generate $\mathrm{K} 17 \mathrm{~F}$ and $\mathrm{pE} 13 \mathrm{~F}$. The proprotein convertase subtilisin/kexin 3 (also named furin) has been shown to cleave in vitro proapelin directly into apelin-13 without generating longer isoforms (13).

For apelin-36 (amino acids 42 to 77 of the preproapelin sequence), the maturation mechanism remains unclear because there are no dibasic motifs upstream from the apelin-36 cleavage site.

Apelin-36 predominates in rat lung, testis, uterus, and in bovine colostrum, whereas both apelin-36 and pE13F have been detected in rat mammary gland $(4,10)$. The predominant forms

\section{Preproapelin sequences}

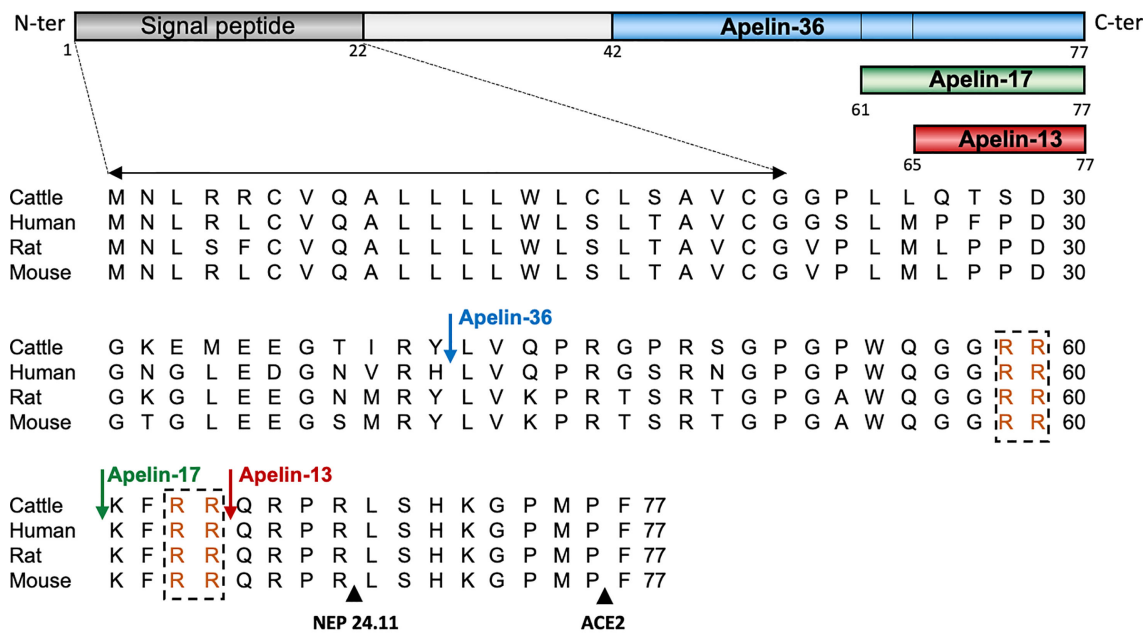

Molecular forms of apelin detected in vivo in rodents and humans

Apelin-36 LVQPRGSRNGPGPWQGGRRKFRRQRPRLSHKGPMPF

Apelin-17 (K17F)

Pyroglutamyl form of apelin-13 (pE13F)
KFRRQRPRLSHKGPMPF

pE R P R L S K G P P F

FIGURE 1 | Amino-acid sequences of the apelin precursor, preproapelin, in cattle, humans, rats, and mice, and the molecular forms of apelin detected in vivo. The blue arrow indicates the beginning of the sequence of apelin-36, the green one that of the sequence of apelin-17 (K17F), which is strictly conserved in mammals and the red one that of the apelin-13 sequence. The dibasic doublets (in orange) are framed by black dashed boxes. The black arrows show the cleavage sites by neutral endopeptidase 24.11 (NEP 24.11, EC 3.4.24.11) and angiotensin-converting enzyme 2 (ACE-2, EC 3.4.17.23). The various molecular forms of apelin detected in vivo in mammals: apelin-36, apelin-17, and the pyroglutamyl form of apelin-13. Figure adapted from Ref. (7) with permission from the copyright holders. 
of apelin in rat brain as well as in rat and human plasma are pE13F and K17F, with much lower concentrations of apelin-36 $(11,12)$. Apelin-13 is the most abundant form in the heart (14).

\subsection{Metabolism of Apelin Peptides}

The carboxypeptidase angiotensin-converting enzyme 2 (ACE-2, EC 3.4.17.23) removes the C-terminal phenylalanine residue of apelin-36, K17F or $\mathrm{pE} 13 \mathrm{~F}$, both in vitro and in vivo $(15,16)$ (Figure 1). Moreover, it has recently been shown that neutral endopeptidase 24.11 or neprilysin (EC 3.4.24.11) hydrolyzes the scissile $\mathrm{Arg}^{8}$-Leu ${ }^{9}$ and $\mathrm{Arg}^{4}-\mathrm{Leu}^{5}$ peptide bonds of K17F and pE13F, respectively (Figure 1), generating two truncated peptides (17) unable to bind the ApelinR. NEP is, thus, the first protease shown to fully inactivate apelin. Synthetic analogs with the modified NEP degradation site ("RPRL" motif) have greater proteolytic stability in vitro while maintaining receptor affinities, highlighting the importance of this region for the full agonist activity of apelin (18).

\section{ANOTHER ENDOGENOUS LIGAND FOR THE APELIN RECEPTOR: ELABELA/APELA}

A second endogenous ligand of the ApelinR, apela (apelin receptor early endogenous ligand, also known as Elabela/ Toddler (encoded by a gene on chromosome 4) was discovered in $2013(19,20)$. There is little sequence identity between apelin and apela, but both originate from precursors which are processed to generate several isoforms (21).

The gene for apela encoded a 54-amino acid precursor. The 22 aa signal peptide is removed to generate apela-32, which is secreted and bioactive $(22,23)$. The cleavage of apela- 32 by furin to produce two fragments composed of 21 and 11 amino acids apela-22 and apela-11, respectively - has been predicted (19, 20). The shortest C-terminal apela- 11 fragment is fully conserved between species. Apela-32 and apela-22 display subnanomolar affinity for the ApelinR, whereas apela-11 is less active $(22,24)$. Apela is broadly expressed during development. In adults, apela mRNA levels are high in the prostate and kidney (25). In addition, the circulating apela in the bloodstream may originate at least partly from the endothelial cells of arterial vessels (22). For a review on apela see (21).

\section{PHARMACOLOGICAL CHARACTERIZATION OF THE APELIN RECEPTOR}

The various molecular forms of apelin (apelin-36, K17F and pE13F) have subnanomolar affinities for the ApelinR $(26,27)$. Structurefunction studies combining molecular modeling and site-directed mutagenesis have shown that the $\mathrm{Arg}^{2}, \mathrm{Arg}^{4}$, and $\mathrm{Lys}^{8}$ residues of $\mathrm{pE} 13 \mathrm{~F}$ interact with acidic aa residues of the ApelinR, located at its surface: Glu 172, Asp 282 and Asp 92, respectively (28).
Numerous studies have described the ApelinR signaling pathways activated by the different molecular forms of apelin. Apelin-36, K17F, and pE13F have similar abilities (in the subnanomolar range) to inhibit forskolin-induced cAMP production in Chinese Hamster Ovary (CHO) cells expressing the rat ApelinR and in Human Embryonic Kidney (HEK) cells expressing the human ApelinR (2, 9, 26, 29). Hosoya et al. showed that pertussis toxin blocked the inhibition of cAMP production induced by apelin-36 and $\mathrm{pE} 13 \mathrm{~F}$, demonstrating the coupling of the ApelinR to $G \alpha_{i}$ (4). This finding was confirmed by Masri et al., who reported the preferential coupling of ApelinR to the $\mathrm{G \alpha}_{\mathrm{i} 1}$ and $\mathrm{G} \alpha_{\mathrm{i} 2}$ proteins $(30,31)$. Apelin-36, K17F, and pE13F also increase $\left[\mathrm{Ca}^{2+}\right]_{\mathrm{i}}$ mobilization in Ntera 2 human teratocarcinoma $(\mathrm{NT} 2 \mathrm{~N})$ cells, in cells derived from basophils (RBL-2H3) and in HEK cells stably expressing the human ApelinR (26, 32-34). Morever, Hus-Citharel et al. showed that K17F decreases (AngII)-induced $\left[\mathrm{Ca}^{2+}\right]_{\mathrm{i}}$ mobilization in glomerular arterioles through the production of nitric oxide (NO) (35). Interestingly, several studies have shown that the stimulation of the ApelinR by apelin (K17F, pE13F) induces vasodilation and modulates vascular tone through $\mathrm{NO}$ production (35-38).

Activation of the apelin/APJ system can also induce a cascade of intracellular signaling kinases that regulate cell function. In human umbilical vein endothelial cells (HUVEC) and in $\mathrm{CHO}$ cells expressing the mouse ApelinR, activation of the apelin/APJ system induces activation of the phosphatidylinositol 3-kinase (PI3K)/Akt and the Extracellular Regulated Kinases (ERK1/2) pathways, stimulating phosphorylation of the S6 ribosomal protein kinase (p70S6K) $(31,39,40)$. D'Aniello et al. showed that apelin induces phosphorylation of p70S6K in murine embryonic stem cells via an ERK1/2-dependent pathway (41). ERKs are phosphorylated in $\mathrm{CHO}$ cells stably expressing the mouse ApelinR in a $\mathrm{G}_{\mathbf{i}}$-protein-dependent, protein kinase $\mathrm{C}$ (PKC)-dependent, and Ras-independent manner (30, 39).

Like most GPCRs, upon the binding of agonist ligands, the ApelinR elicits the recruitment of $\beta$-arrestins and their subsequent internalization through a clathrin-dependent mechanism $(26,27,29,34,37,42)$. Ser 348 at the C-terminus of the ApelinR has been identified as a crucial phosphorylation site for the interactions of this receptor with GRK2/5, $\beta$-arrestin1/2, and for its internalization (43). Furthermore, the C-terminal Phe residue of $\mathrm{pE} 13 \mathrm{~F}$ is embedded at the bottom of the binding site, in a hydrophobic cavity composed by Trp 152 in TMIV and Trp 259 and Phe 255 in TMVI (27).

Site-directed mutagenesis experiments revealed that Phe 255 and Trp 259, through their interactions with the C-terminal Phe residue of $\mathrm{pE} 13 \mathrm{~F}$, were crucial for ApelinR internalization, but played no role in apelin binding or $\mathrm{G \alpha}_{\mathbf{i}}$ protein coupling. The C-terminal Phe residue of apelin is, thus, a key residue triggering ApelinR internalization $(29,44)$. Deletion of the C-terminal Phe residue of K17F (K16P) and the replacement of this residue with an alanine (K17A) strongly decrease the ability of the peptide to trigger ApelinR internalization, without affecting its affinity for the ApelinR or its ability to activate Goi-coupling $(16,27,29)$. All these data indicate functional 
dissociation between ApelinR $\mathrm{G}_{\mathrm{i}}$-coupling and receptor internalization. This implies that the ApelinR exists in different active conformations, depending on the ligand fitting into the binding site, leading to the activation of different signaling pathways, and different subsequent biological effects (27). These findings suggest that ApelinR may display 'functional selectivity' or 'biased signaling', by coupling with $\mathrm{G}_{i}$ protein or recruiting $\beta$-arrestin 1 and 2 . This hypothesis was confirmed by Ceraudo et al., who showed that K17F activates ERK1/2 in a $\beta$ arrestin-dependent and $G_{i}$ protein-dependent manner, whereas K16P activates only the $G_{i}$ protein (45). This functional selectivity of apelin peptides indicates that $\beta$-arrestindependent ERK1/2 activation, but not $\mathrm{G}_{\mathrm{i}}$-dependent signaling, may contribute to the decrease in blood pressure (BP) induced by $\mathrm{K} 17 \mathrm{~F}$. Indeed, when $\mathrm{pE} 13 \mathrm{~A}$ and $\mathrm{K} 16 \mathrm{P}$ are injected intravenously in rats, they lost their capacity to decrease arterial $\mathrm{BP}$ when compared with the corresponding natural peptides, $\mathrm{pE} 13 \mathrm{~F}$ and K17F (29, 46). Moreover, the internalized ApelinR/pE13F complex is rapidly recycled to the cell surface through a Rab4dependent mechanism whereas the internalized ApelinR/apelin36 complex is targeted for degradation in lysosomes by Rab7 (47), showing that the trafficking of the ApelinR depends upon the ligand used to activate the receptor. These differences are consistent with studies showing that apelin-36 induces sustained, strong desensitization of the ApelinR, whereas the desensitization induced by $\mathrm{pE} 13 \mathrm{~F}$ is transient (30). The apelin isoforms therefore display subtle differences in pharmacological properties, which may influence their physiological actions.

Moreover, like many GPCRs, ApelinR may also form heterodimers in vitro with other GPCRs. ApelinR has been shown to dimerize with the AngII type 1 receptor (AT1R), leading to an inhibition of AngII signaling by apelin (48-50). ApelinR may also heterodimerize with the $\kappa$-opioid receptor, leading to an increase in cell proliferation through an increase in PKC activity and a decrease in protein kinase A activity (51). In HUVEC cells, ApelinR has been shown to heterodimerize with bradykinin type 1 receptor, leading to an increase in cell proliferation and the phosphorylation of eNOs through a $\mathrm{G}_{\mathrm{q}}$ protein-dependent PKC signaling pathway (52).

\section{DISTRIBUTION OF APELIN AND ITS RECEPTOR}

\subsection{In the Brain}

Preproapelin is heterogeneously distributed between different brain structures $(3,8,10,26,53)$. The distribution of apelinergic neurons in the adult rat brain has been studied using a polyclonal antibody with a high affinity and selectivity for K17F, which also recognizes pE13F and apelin-36 (11, 37, 54). Apelin-immunoreactive (IR) neuronal cell bodies are abundant in the hypothalamus and the medulla oblongata. These structures are involved in neuroendocrine control, food intake and the regulation of BP. They are abundant in the supraoptic nucleus (SON), the magnocellular part of the paraventricular nucleus (PVN), the arcuate nucleus, the nucleus ambiguus and the lateral reticular nucleus (54) (Figure 2).
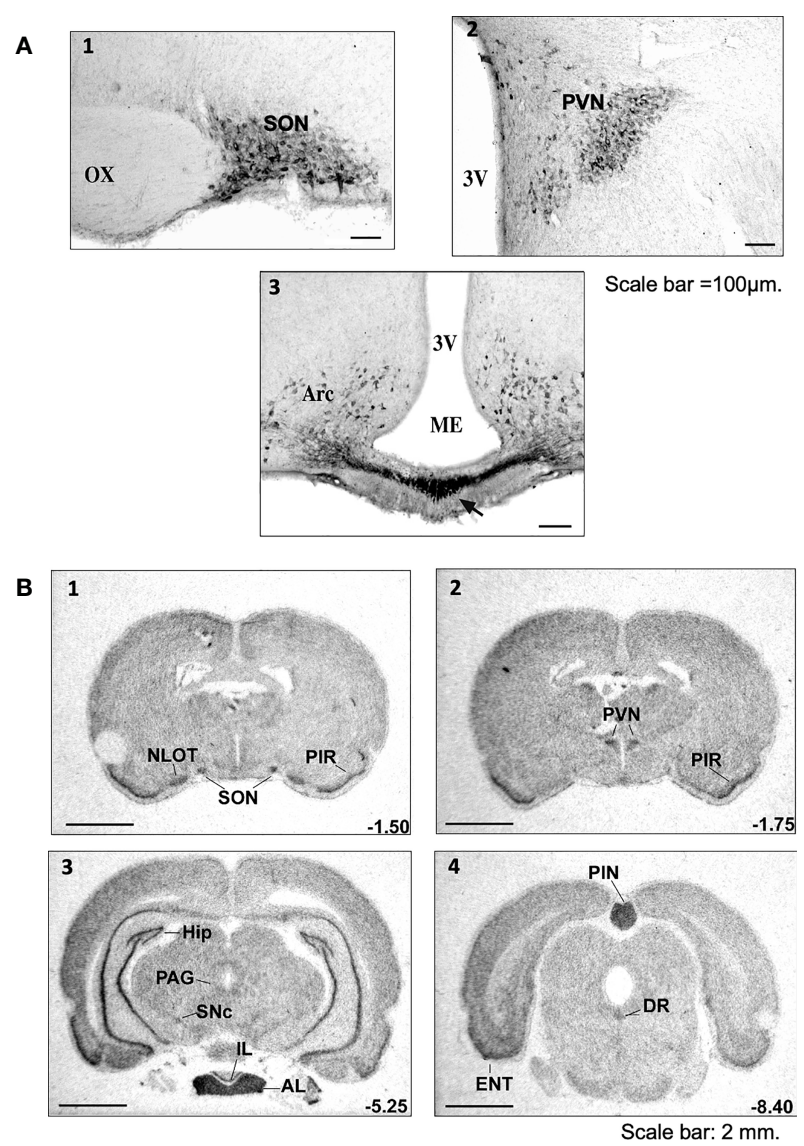

FIGURE 2 | Distribution of apelinergic neurons and apelin-R mRNA in the adult rat brain (A) Coronal sections illustrating the distribution of apelin-containing cell bodies and nerve fibers in (1) the SON, (2) the PVN and (3) the Arc and ME of colchicine-treated adult rats. In the SON, the apelin-immunoreactive neurons and the nerve fibers are concentrated mostly in the ventral part of the nucleus. In the PVN, apelin-positive cell bodies and nerve fibers are found mostly in the magnocellular part of the nucleus. Numerous neuronal cell bodies were observed within the Arc, together with a higher density of nerve fibers in the internal layer of $\mathrm{ME}$ than in the external layer. Scale bar $=100 \mu \mathrm{m}$. Figure adapted from Ref. (11, 54) with permission from the copyright holders. (B) Distribution of the rat ApelinR $m R N A$ expression in the adult rat brain. The figures were scanned directly from the X-ray film. Representative frontal sections, at anteriorities determined from the bregma indicated in the lower right corner, from 1 to 4 , were hybridized with the ApelinR antisense cRNA probe. Scale bar: $2 \mathrm{~mm}$. Figure adapted from Ref. (11) with permission from the copyright holders. $\mathrm{AL}$, anterior lobe of the pituitary gland; Arc, arcuate nucleus of the hypothalamus; DR, dorsal raphe nucleus; ENT, entorhinal cortex; HIP, hippocampus; IL, intermediate lobe of the pituitary gland; ME, median eminence; NLOT, nucleus of the lateral olfactory tract; OX, optic chiasma; PAG, periaqueductal gray matter; PIN, pineal gland; PIR, piriform cortex; PVN, paraventricular nucleus of the hypothalamus; SNc, pars compacta of the substantia nigra; SON, supraoptic nucleus; 3V, third ventricle.

Conversely, the density of apelin-IR nerve fibers and nerve endings is high in the inner layer of the median eminence and in the posterior pituitary $(37,55)$, suggesting that, like magnocellular vasopressinergic and oxytocinergic neurons, the apelinergic neurons originating from the PVN and the SON project onto the posterior pituitary. Apelin was subsequently shown to colocalize with arginine-vasopressin (AVP) $(11,56)$ and oxytocin $(55,57)$ in 
magnocellular neurons. Apelin-IR cell bodies and fibers have also been identified in the subfornical organ (SFO), the organum vasculosum of the lamina terminalis (OVLT) and the median preoptic nucleus, all of which are involved in controlling drinking behavior $(58,59)$.

The ApelinR is also widely distributed in the rat central nervous system (CNS) $(2,3,8)$. ApelinR mRNA has been identified in the piriform and entorhinal cortices, the hippocampus, the pars compacta of the substantia nigra, the dorsal raphe nucleus and the locus coeruleus (Figure 2). The last three of these structures are known to contain the neuronal cell bodies from dopaminergic, serotoninergic and noradrenergic neurons. High levels of apelinR mRNA have also been detected in the SON, PVN, arcuate nucleus, pineal gland and pituitary gland (2). Moreover, in the SON and PVN, the ApelinR $(37,60)$ and AVP receptor types $1 \mathrm{a}(\mathrm{V} 1 \mathrm{a})$ and $1 \mathrm{~b}(\mathrm{~V} 1 \mathrm{~b})$, but not type 2 (V2-R) (61), are coexpressed by magnocellular AVP neurons. This finding provides strong evidence for the existence of an interaction between AVP and apelin.

\subsection{In the Kidney}

The mRNAs encoding preproapelin and ApelinR are expressed in rat and human kidney $(3,26)$. Apelin-like immunoreactivity has also been detected in human endothelial cells from small intrarenal vessels (62). Apelin expression has been detected in rat tubular epithelial cells, glomeruli and vascular epithelial cells (63), but another study reported restriction of apelin expression essentially to isolated cells in the medulla (64). An immunofluorescence study showed apelin to be present in the medullary collecting ducts (CD), with a distribution overlapping with that of aquaporin type 2 water channel (AQP2) (65).

ApelinR mRNA has been detected in the endothelial and vascular smooth muscle cells of rat glomerular arterioles (35). High levels of ApelinR mRNA are present in the glomeruli, reaching levels about eight times higher than those in nephron segments. Expression levels are moderate in all nephron segments $(3,35)$, including the collecting duct (CD), in which V2-R are also expressed (66). ApelinR mRNA levels are highest in the inner and outer stripes of the outer medulla (OM) and in the thick ascending limb (TAL) $(35,64,65,67)$.

\section{MAINTENANCE OF WATER BALANCE BY APELIN AND VASOPRESSIN, THROUGH CENTRAL AND RENAL EFFECTS}

\subsection{Central Effects of Apelin on AVP Neuronal Activity, AVP Release and Diuresis}

AVP, also known as antidiuretic hormone $(\mathrm{ADH})$ is a peptide synthesized and released by hypothalamic magnocellular AVP neurons from the posterior pituitary into the bloodstream, in response to changes in plasma osmolality and volemia $(68,69)$ or under the influence of neurohormones, including natriuretic and angiotensin peptides $(70,71)$. The colocalization of AVP, apelin, $\mathrm{V} 1$ and apelin receptors in magnocellular neurons suggests an interaction between apelin and AVP. This raises the possibility of an effect of apelin in response to osmotic or volemic stimuli. This hypothesis was checked in two animal models. Studies were first performed in the lactating rat, which displays magnocellular AVP neuron hyperactivity, leading to an increase in AVP synthesis and release, to preserve water of the organism for an optimal milk production for the newborns $(72,73)$. In this model, the intracerebroventricular (i.c.v.) administration of apelin (K17F) (11) inhibits the phasic electrical activity of the magnocellular AVP neurons, reduces the release of AVP into the bloodstream and increases diuresis, without modifying sodium and potassium excretion (Figure 3). The second model used was mice deprived of water for $24 / 48 \mathrm{~h}$, a condition known to increase AVP neuron activity and systemic AVP release (75, 76). In this model, i.c.v. K17F administration decreased systemic AVP release (11). These results suggest that apelin is probably released from the SON and PVN AVP cell bodies and inhibits AVP neuron activity and release through direct action on the apelin autoreceptors expressed by AVP/apelin-containing neurons. This mechanism probably involves apelin acting as a natural inhibitor of the antidiuretic effect of AVP.

On the other hand, in the anterior pituitary, apelin is highly co-expressed in corticotrophs and to a much lower extent in somatotrophs, and a high expression of ApelinR mRNA is also found in corticotrophs (77). Moreover, apelin was shown to act as a stimulatory autocrine/paracrine-acting peptide on adrenocorticotropic hormone $(\mathrm{ACTH})$ release, suggesting a role for apelin in the regulation of the hypothalamo-pituitary adrenal (HPA) axis. Since ACTH at the adrenal level is a major stimulus of glucocorticoid secretion (78) and glucocorticoids were shown to increase water excretion possibly via an inhibition of AVP release (79), the aquaretic effect of apelin could also involve this pathway.

\subsection{Renal Effects of Apelin on AVP- Induced Water Reabsorption}

In addition to its central action, the aquaretic effect of apelin may involves a renal action, since apelin and its receptor are both expressed in the kidney $(3,26,35,62)$. Consistent with the presence of ApelinR mRNA in juxtamedullary efferent (EA) and afferent (AA) arterioles, the application of K17F on glomerular arterioles precontracted by AngII treatment induced NOdependent vasorelaxation by inhibiting the Ang-II induced increase in intracellular calcium mobilization (35). This apelindependent vasorelaxation observed in the muscular EA, which give rise to the vasa recta, should result in an increase in renal blood flow, contributing to an increase in diuresis (35).

By stimulating V2-R in CD, AVP is known to induce an increase in CAMP production and to activate protein kinase A, which phosphorylates the AQP2. This results in the insertion of phosphorylated AQP2 into the apical membrane of the principal cells of the $\operatorname{CD}(80,81)$, leading to water reabsorption, decreasing diuresis and plasma osmolality (Figure 3). The presence of ApelinR mRNA in the CD (35, 


\section{AVP and APELIN : the YIN and the YANG of WATER BALANCE}

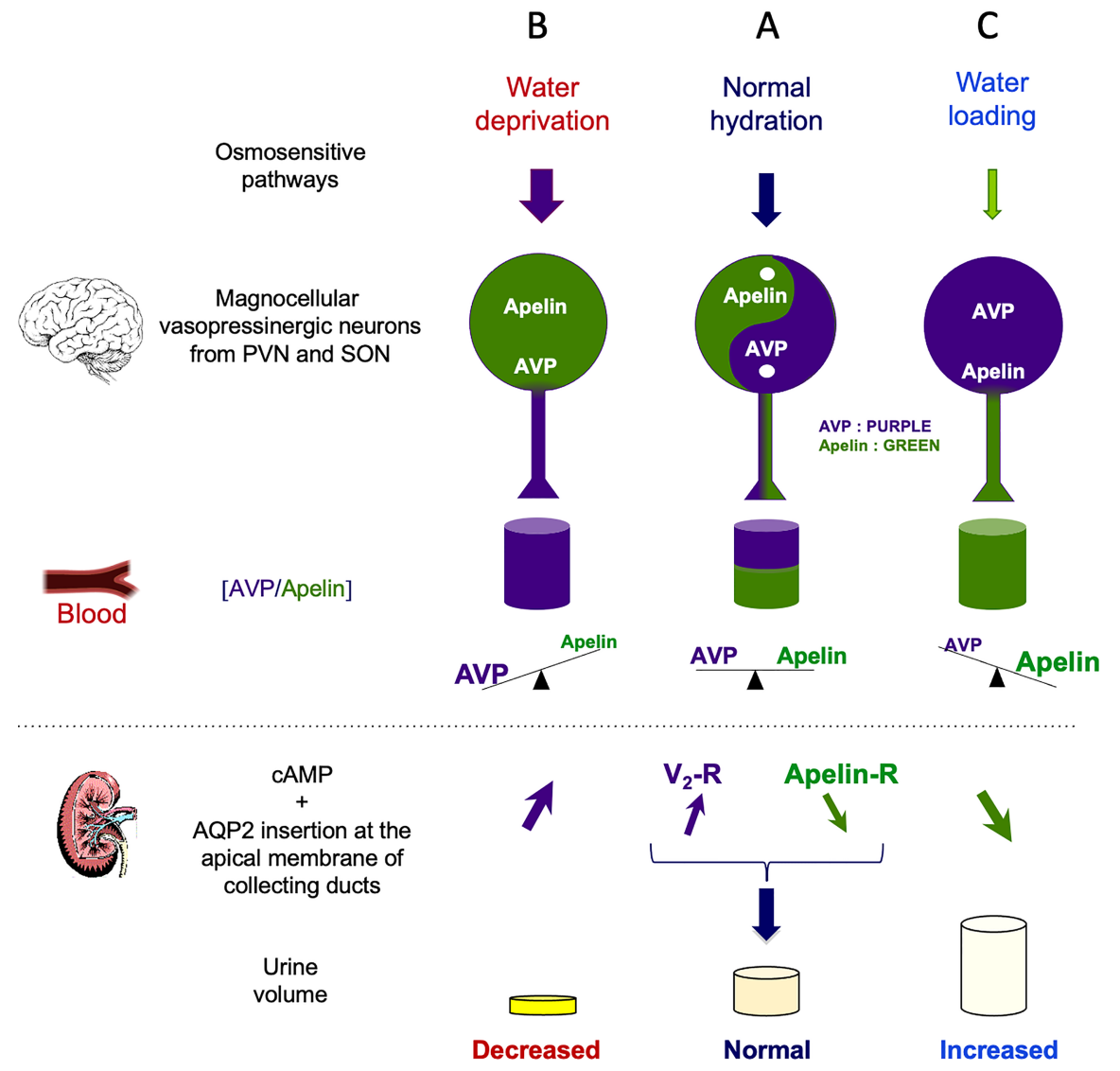

FIGURE 3 | Vasopressin (AVP) and apelin: the yin and yang of water balance (A) In physiological conditions, apelin (green) and AVP (purple) are released in balanced proportions from the magnocellular AVP neurons, at levels appropriate for plasma osmolality. In the collecting duct of the kidney, AVP acts on V2-R to increase cAMP production and aquaporin-2 (AQP2) insertion into the apical membrane, leading to water reabsorption. Apelin has the opposite effect, through its action on the ApelinR. Water reabsorption is adequate in physiological conditions. (B) Following water deprivation in rodents: 1) AVP is released from magnocellular vasopressinergic neurons into the bloodstream more rapidly than it is synthesized, causing a depletion of AVP magnocellular neuronal content; 2) apelin release into the bloodstream decreases and apelin accumulates in magnocellular neurons. Thus, after dehydration, AVP and apelin are regulated in opposite manners, to facilitate systemic AVP release and suppress diuresis. (C) Following water loading in rodents: 1) AVP release is decreased from magnocellular vasopressinergic neurons into the bloodstream, causing an accumulation in AVP magnocellular neuronal content; 2) apelin release into the bloodstream increases, leading to a depletion of apelin magnocellular neuronal content. Thus, after water loading, AVP and apelin are regulated in opposite manners, to facilitate systemic apelin release and to increase aqueous diuresis. Figure adapted from Ref. (74) with permission from the copyright holders.

67) suggests that apelin could act as an aquaretic peptide through a direct action on this nephron segment. Consistent with this hypothesis, the intravenous injection of $\mathrm{K} 17 \mathrm{~F}$ in increasing doses in lactating rats or the continuous intravenous administration of apelin-13 administered for $24 \mathrm{~h}$ in alert male Sprague-Dawley alert rats (82) strongly increased diuresis in a dose-dependent manner, with a concomitant significant decrease in urine osmolality and no change in the excretion of $\mathrm{Na}^{+}$and $\mathrm{K}^{+}$. Under these conditions, a significant decrease in apical AQP2 immunolabeling in the CD, with a corticomedullary gradient, was observed (83) (Figure 3). This finding is consistent with the inhibition, by $\mathrm{K} 17 \mathrm{~F}$, in the medullary $\mathrm{CD}$, of the cAMP production induced by (deamino-Cys ${ }^{1}, \mathrm{D}-\mathrm{Arg}^{8}$ )-vasopressin (dDAVP), a specific and selective V2-R agonist (83). These findings suggest that apelin may act as an aquaretic peptide through direct action on CD. Further evidence in support of this conclusion was recently provided by studies in a highly differentiated mouse cortical CD cell line (mpkCCD) expressing the V2-R and the ApelinR (84). The authors showed in this cell line that apelin-13 decreased the dDAVP-induced phosphorylation and apical membrane expression of AQP2 after 30-60 minutes of treatment, and decreased ADAVP-induced AQP2 mRNA and protein levels after 8-24 h of treatment (84). Furthermore, another study has shown that $\mathrm{pE} 13 \mathrm{~F}$ has diuretic effects potentially involving the $\mathrm{cAMP} /$ protein kinase $\mathrm{A} /$ soluble prorenin receptor pathway in the CD (85). Thus, the aquaretic effect of apelin is due not only to a central effect, inhibiting AVP release into the bloodstream, 
but also to a direct effect of apelin in the kidneys, increasing renal blood flow and counteracting the antidiuretic effect of AVP mediated via the V2-R in CD (Figure 3).

These results also show that apelin and AVP have opposite effects on the CD, contributing to the control of plasma osmolality by regulating water reabsorption by the kidney.

These results are consistent with those of other studies reporting an aquaretic role of apelin in rodents $(82,84-87)$. In addition, apelin gene expression in the brain has also been reported to be hydrationsensitive (88). It must also be taken into account that Elabela/apela which has the same affinity as apelin for the apelinR, has been shown to stimulate urine output and water intake in adult rats (82, 87) suggesting that Elabela/apela may therefore play with apelin a role in the regulation of body fluid homeostasis.

Studies on ApelinR ${ }^{-/-}$mice $(89,90)$ have shown that water deprivation significantly decreases urine volume (by 61\%) and increases urine osmolality (by 59\%) in wild-type mice, with similar, but non-significant changes observed in ApelinR ${ }^{-/-}$ mice $(-25 \%$, and $+26 \%$ respectively), suggesting that the ApelinR $^{-/-}$mice did not concentrate their urine to the same extent as wild-type mice. This effect was not related to an inability of ApelinR $^{-/-}$mice to increase their plasma AVP levels following water deprivation. In normal hydration conditions, plasma AVP levels in ApelinR ${ }^{-/-}$mice $(23.3 \mathrm{pg} / \mathrm{ml}$ ) were $40 \%$ lower than those in wild-type mice $(39.5 \mathrm{pg} / \mathrm{ml})$. Following water deprivation, plasma AVP levels in ApelinR ${ }^{-/-}$and wild-type mice were similar (52.9 and $57.7 \mathrm{pg} / \mathrm{ml}$ respectively). This showed that water deprivation increased plasma AVP levels by $127 \%$ in ApelinR $\mathrm{R}^{-/-}$mice whereas only by $46 \%$ in wild-type mice.

The authors also showed that treatment with dDAVP increased urinary osmolality more efficiently $(+29 \%)$ in wild-type mice than in ApelinR $^{-/-}$mice. These observations suggest that the defect in water metabolism observed in ApelinR $\mathrm{R}^{-/-}$mice is not due to a decrease in plasma AVP levels but may result from a deficiency at the kidney level, like a decrease in the density of renal V2-R binding sites or in the signaling response of the V2R which remains to be investigated. These data are not in line with the aquaretic effect of apelin and apelin analogs $(38,82,83,86,87,91)$ but it cannot be excluded that the total absence of ApelinRs during fetal and adult life could elicit compensatory mechanisms, leading to these opposite effects on urine output and urine osmolality.

\subsection{Opposite Patterns of Vasopressin and Apelin Regulation Following Water Deprivation}

\subsubsection{In Rodents}

The colocalization of apelin and AVP, and their opposite actions on diuresis raise questions about the regulation of these peptides to maintain body fluid homeostasis.

Following water deprivation in rodents, AVP is released into the bloodstream more rapidly that it is synthesized, causing a depletion of AVP neuronal content in magnocellular vasopressinergic neurons (92). In parallel, water deprivation decreases plasma apelin levels and induces an increase in apelin neuronal content in magnocellular vasopressinergic neurons $(11,56)$. Thus, following water deprivation, apelin accumulates in the vasopressinergic neurons rather than being released. This increase in apelin neuronal content observed in dehydrated rats is markedly reduced by the i.c.v. administration of a selective V1 receptor antagonist, whereas the i.c.v. infusion of AVP has effects on neuronal apelin concentration similar to those of dehydration, this effect being selectively blocked by the co-administration of a V1 receptor antagonist (56). The apelin and AVP responses to dehydration are, therefore, opposite (11, 92). These results imply that AVP and apelin are released separately by the magnocellular vasopressinergic neurons by which they are produced. Consistent with this hypothesis, double-immunolabeling confocal microscopy studies have shown that a large proportion of apelin immunoreactivity colocalizes with AVP in magnocellular neurons in the SON and the PVN, although these two peptides are found in different subcellular compartments $(11,56)$.

These studies show that the cross-regulation of apelin and AVP, in response to osmotic stimuli, has a physiological purpose: the maintenance of water balance in the body, through the prevention of water excretion by the kidney after water deprivation, and the promotion of water excretion after water loading.

\subsubsection{In Humans}

Such cross-regulation of apelin and AVP in response to osmotic stimuli has also been studied in humans. The relationship between osmolality and plasma concentrations of apelin and AVP was investigated in healthy volunteers (12) after the infusion of hypertonic saline for $2 \mathrm{~h}$ to increase plasma osmolality or after 30 minutes of oral water loading to decrease plasma osmolality.

Increases in plasma osmolality were accompanied by a simultaneous increase in plasma AVP levels and a decrease in plasma apelin levels. Conversely, decreases in plasma osmolality led to lower plasma AVP levels and a rapid increase in plasma apelin levels (12). These observations are consistent with plasma osmolality acting as a major physiological regulator of plasma apelin levels in humans. Furthermore, the opposite patterns of apelin and AVP regulation by osmotic stimuli in humans are consistent with findings for rodents subjected to water deprivation. This strongly suggests that, like AVP, apelin participates in the maintenance of body fluid homeostasis in humans, as it does in rodents. Apelin and AVP can therefore be seen as the yin and yang of body fluid homeostasis.

\section{THE APELIN/AVP BALANCE AND HYPONATREMIA}

\subsection{Hyponatremia}

Hyponatremia, defined by a plasma sodium concentration below $135 \mathrm{mmol} / \mathrm{l}$, is the most common electrolyte disorder in hospitalized patients. Various conditions have been associated with hyponatremia, including chronic heart failure, chronic kidney disease, liver cirrhosis, diuretic treatment and the Syndrome of Inappropriate Antidiuresis (SIAD), in which AVP secretion occurs in the absence of an osmotic or hemodynamic 
abnormality (93). It is important to recognize hyponatremia, because this condition is associated with high mortality rates (94-96) and can be a marker of underlying disease.

\subsection{Syndrome of Inappropriate Antidiuresis}

SIAD, previously known as the syndrome of inappropriate secretion of antidiuretic hormone (SIADH), is the most frequent cause of hyponatremia. Many clinical conditions may cause SIAD, including tumors, which may secrete AVP ectopically, central nervous system disorders and pulmonary diseases. SIAD may also result from the induction of increases in AVP secretion by various drugs, including tricyclic antidepressants, serotonin reuptake inhibitors and opiates, and/or from potentiation of the effects of AVP by drugs such as carbamazepine, chlorpropamide and non-steroidal antiinflammatory drugs (97).

In SIAD, plasma AVP levels increase in a manner that is inappropriate relative to plasma osmolality (93). By acting on V2-R present in the CD of kidneys, the increased AVP levels stimulate cAMP production, leading to the insertion of AQP2 into the apical membrane of $\mathrm{CD}$, resulting in higher levels of water reabsorption, lower levels of diuresis, and hyponatremia. Hyponatremia causes water entry into the cells due to the hypotonic state (98). Its symptoms result mostly from the enlargement of cells in the central nervous system, and their severity is dependent on serum sodium concentration. Severe symptoms, such as coma, convulsions, and respiratory arrest are usually associated with acute-onset severe hyponatremia. Less severe symptoms, such as headache, irritability, nausea/vomiting, mental slowing, and confusion, are observed in chronic hyponatremia (99).

Plasma apelin and AVP levels are regulated in opposite manners by osmotic stimuli in healthy subjects; this observation led to investigate the apelin response to the AVP osmoregulation defect in SIAD (100). In SIAD patients, sex- and age-adjusted plasma levels for apelin and copeptin (a biomarker of AVP release into the bloodstream in humans) are $26 \%$ and $75 \%$ higher, respectively, than those in healthy subjects (100). In $86 \%$ of SIAD patients, the plasma apelin/copeptin ratio lies outside the predicted range, highlighting the primary osmoregulatory defect in these patients. The abnormal apelin/ AVP balance in hyponatremic SIAD patients may contribute to water retention (100). This has led to hypothesize that activation of the ApelinR with an ApelinR agonist might counteract AVPinduced water reabsorption, thereby correcting hyponatremia.

\subsection{Effects of the Metabolically Stable Apelin-17 Analog LIT01-196 in an Experimental Model of Hyponatremia}

\subsubsection{Development and Pharmacological Properties} of LIT01-196

Endogenous apelin peptides have a short half-life in vivo. Gerbier et al. showed that K17F and $\mathrm{pE} 13 \mathrm{~F}$ have half-lives in mouse plasma of 4.6 and 7.2 minutes, respectively (38), and Murza et al. showed that $\mathrm{pE} 13 \mathrm{~F}$ has a half-life of 14 minutes in rat plasma (101). For apelin36 , Japp et al. suggested, based on experiments conducted in healthy human subjects, that the half-life of apelin-36 is less than five minutes (102). The half-life of $\mathrm{K} 17 \mathrm{~F}$ in vivo in the bloodstream after intravenous administration is $44 \mathrm{~s}$ in mice and $50 \mathrm{~s}$ in rats (86). These short half-lives result from the rapid metabolism of apelins by enzymes, such as ACE2 and NEP $24.11(16,17)$.

The short half-life of apelin in vivo has encouraged the development of metabolically stable apelin analogs for potential therapeutic applications. Numerous approaches (Table 1), such as PEGylation (107-109, 112, 113), synthetic modifications to the RPRL motif of apelin (18), palmitoylation and the use of unnatural amino acids $(38,103,107,114,115)$, or main-chain modifications (cyclization) $(106,116,117)$, have now been used to increase the half-life of apelin peptides. Recent studies have reported the development of nonpeptidic ApelinR agonists that mimic the signaling properties of apelin, some of them are orally active (Table 1) $(104,110,111)$.

Most studies aiming to develop apelin analogs have focused on pE13F $(38,103,105,106,115-117)$ and apelin-36 (108, 109, 112) (Table 1). However, K17F, which has an affinity 10 times higher than that of $\mathrm{pE} 13 \mathrm{~F}$ for human ApelinR, induces $\beta$-arrestin recruitment and the internalization of the rat ApelinR 10 to 30 times more strongly than $\mathrm{pE} 13 \mathrm{~F}$, and also decreases arterial $\mathrm{BP}$ more effectively $(29,38)$.

Following these findings, metabolically stable K17F analogs have recently been developed $(38,107)$. Gerbier et al. used an original strategy for improving the protection of endogenous peptides against enzymatic degradation, based on the introduction of a fluorocarbon chain (FC) directly into the N-terminal part of K17F, generating LIT01-196 (Figure 4). This compound has a high affinity for the ApelinR $\left(K_{i}=0.08 \mathrm{nM}\right)$ and is much more stable in plasma (half-life $>24 \mathrm{~h}$ ) than K17F (4.6 min). LIT01-196 is remarkably resistant to plasma degrading-enzymes, with $>90 \%$ of the peptide remaining unmodified after $24 \mathrm{~h}$ of incubation with mouse plasma at $37^{\circ} \mathrm{C}$. LIT01-196 displays full agonist activity for cAMP production, ERK1/2 phosphorylation (nanomolar range), $\beta$-arrestin recruitment and the induction of ApelinR internalization (subnanomolar range) (38). Moreover, LIT01-196 has an in vivo half-life of $28 \mathrm{~min}$ in the bloodstream (versus $50 \mathrm{sec}$ for K17F) after intravenous administration and 156 min after s.c. administration in alert control rats and was shown not to enter the brain after s.c. administration (38). The increase of the in vivo half-life of LIT01196 in the blood circulation is probably due to the $69 \%$ binding of LIT01-196 to plasma proteins leading to the protection from enzymatic degradation and the reduction of renal clearance (38).

\subsubsection{Effects of LIT01-196 on AVP Release and AVP- Induced Antidiuresis in Control Animals}

The central administration of LIT01-196 significantly decreases dehydration-induced systemic AVP release, and is 160 times more effective than K17F (38). These data suggest that LIT01-196 after i.c.v injection, like $\mathrm{K} 17 \mathrm{~F}$, rapidly reaches the hypothalamic structures, the PVN and the SON, to stimulate the ApelinR expressed by AVP neurons, inhibit AVP release into the bloodstream and increase diuresis.

The effects of LIT01-196 were then investigated at the kidney level. First, in vitro in mpkCCD cells, LIT01-196 decreases 
TABLE 1 | Development of Apelin-R agonists.

\begin{tabular}{|c|c|c|c|c|c|c|}
\hline & $\begin{array}{l}\text { Affinity } \\
\text { (Ki, nM) }\end{array}$ & $\begin{array}{l}\text { cAMP production } \\
\text { inhibition }\left(\mathrm{IC}_{50}, \mathrm{nM}\right)\end{array}$ & $\begin{array}{l}\beta \text {-arrestin } \\
\left(\mathrm{EC}_{50}, \mathrm{nM}\right)\end{array}$ & $\begin{array}{l}\text { Ex vivohalf-life } \\
\text { in plasma (min) }\end{array}$ & $\begin{array}{l}\text { In vivo half-life in } \\
\text { bloodstream (min) }\end{array}$ & Diuresis \\
\hline \multicolumn{7}{|l|}{ PEPTIDIC ApelinR AGONISTS } \\
\hline \multicolumn{7}{|l|}{ Apelin-13/pE13F and pE13F analogs } \\
\hline pE-R-P-R-L-S-H-K-G-P-M-P-F (38, 82, 101, 103, 104) & 0.5 & 1.8 & $68-300$ & $\sim 10$ & $<1$ after iv route & $\begin{array}{c}\mathbf{+} \\
(82,87,91)\end{array}$ \\
\hline pE-R-P-R-L-S-H-K-G-P-Nle-P-F(L- $\left.\alpha \mathrm{CH}_{3}\right)(101,105)$ & 0.3 & 0.07 & - & $>120$ & - & - \\
\hline MM07: Cyclo(1-6)C-R-P-R-L-C-H-K-G-P-M-P (106) & 300 & - & 2130 & - & 17 & - \\
\hline pE-R-P-R-L-S-H-K-G-P-Nle-1 Nal-D- $\alpha-M e-Y(O B n)$ (103) & 0.08 & 3.8 & 36 & 438 & 26 & - \\
\hline \multicolumn{7}{|l|}{ Apelin-17 (K17F) and K17F analogs } \\
\hline K17F: K-F-R-R-Q-R-P-R-L-S-H-K-G-P-M-P-F $(38,86)$ & 0.06 & 0.30 & 15 & 4.6 & $<1$ after iv route & $\stackrel{+}{+}$ \\
\hline Fmoc-(PEG) $)_{6}-N M e L e u-17 A 2(107)$ & 0.55 & - & - & 1620 & - & - \\
\hline $\begin{array}{l}\text { P92: Ac-K-F-(D)R-R-(D)Q-R-P-R-(D)L-S-Aib-K-(D)A-P-Nle-P- } \\
\text { 4Br(F) (38) }\end{array}$ & 0.09 & 0.56 & 4 & 24 & - & $\begin{array}{c}++ \\
(38)\end{array}$ \\
\hline $\begin{array}{l}\text { LIT01-196: } \mathrm{CF}_{3}\left(\mathrm{CF}_{2}\right)_{7}\left(\mathrm{CH}_{2}\right)_{2} \mathrm{C}(\mathrm{O})-\mathrm{K}-\mathrm{F}-\mathrm{R}-\mathrm{R}-\mathrm{Q}-\mathrm{R}-\mathrm{P}-\mathrm{R}-\mathrm{L}-\mathrm{S}-\mathrm{H}- \\
\text { K-G-P-M-P-F }(38,86)\end{array}$ & 0.08 & 1.71 & 16 & $>1440$ & 156 after sc route & $\begin{array}{c}++ \\
(38,86)\end{array}$ \\
\hline \multicolumn{7}{|l|}{ Apelin- 36 and apelin- 36 analogs } \\
\hline $\begin{array}{l}\text { Apelin-36: L-V-Q-P-R-G-S-R-N-G-P-G-P-W-Q-G-G-R-R-K- } \\
\text { F-R-R-Q-R-P-R-L-S-H-K-G-P-M-P-F }(4,9,46,102)\end{array}$ & 2.4 & 0.5 & - & - & $<5$ & - \\
\hline 40kDa-PEG-Apelin-36 $(108,109)$ & 0.3 & 1.7 & 2 & - & $\sim 20$ & - \\
\hline \multicolumn{7}{|l|}{ NON-PEPTIDIC ApelinR AGONISTS } \\
\hline CMF-019 (104) & 2.6 & 0.1 & 224 & 38 & - & - \\
\hline AMG $986(110)$ & - & 0.23 & 0.25 & - & $\begin{array}{l}144 \text { after iv route } \\
\text { Orally active }\end{array}$ & - \\
\hline BMS-986224 (111) & 0.07 & 0.02 & 7.9 & - & Orally active & - \\
\hline
\end{tabular}

-, not determined; G, glycine; $P$, proline; $A$, alanine; $V$, valine; L, leucine; I, isoleucine; $M$, methionine; $C$, cysteine; $F$, phenylalanine; $Y$, tyrosine; $W$, tryptophan; $H$, histidine; $K$, lysine; $R$, arginine; Q, glutamine; $N$, asparagine; E, glutamic acid; D, aspartic acid; S, serine; T, threonine; Aib, aminoisobutyric acid; Y(OBn), tyrosine(Obenzyl); Nle, norleucine; 1Nal, 1naphthylalanine; $4 \mathrm{Br}(F)$, 4-bromo-phenylalanine; PEG, polyethyleneglycol; Fmoc, 9-fluorenylmethyloxycarbonyl.

dDAVP-induced cAMP production and apical cell surface expression of phosphorylated AQP2. These data suggested that systemic LIT01-196 administration in rats could induce like K17F an increase in aqueous diuresis. Indeed, LIT01-196 and tolvaptan (a V2-R) used as a reference aquaretic agent, administered at an equimolar dose of $900 \mathrm{nmol} / \mathrm{kg}$ by s.c. route, increase $24 \mathrm{~h}$ urine output similarly, by $79 \%$ and $77 \%$, respectively, and decrease urinary osmolality by $52 \%$ and $40 \%$, respectively, in control rats with normal natremia (86). This increase in urine output is associated with a significant increase in water intake in the tolvaptan group $(+37 \%)$ and a slight increase in water intake in the LIT01-196 group $(+11 \%)$. The sodium excretion fraction is unaffected by the administration of LIT01-196 or tolvaptan (86). These data suggest that LIT01-196 inhibits AVP-induced cAMP production in the $\mathrm{CD}$, thereby inhibiting the insertion of AQP2 into the apical membrane, inhibiting water reabsorption by the kidney and increasing aqueous diuresis (Figure 4). Moreover, repeated s.c. administrations of LIT01-196 are not associated with renal failure or histological alterations of the kidney, and no change in plasma sodium, potassium, and glucose levels are observed in control rats (86).

On the other hand, LIT01-196 induces, like K17F, a vasorelaxation of the rat juxtamedullary arterioles that give rise to the vasa recta (38), suggesting that LIT01-196 can, like K17F, increase medullary blood flow and, therefore, diuresis (35). Thus, through its central and renal effects, LIT01-196 appears to be an effective aqueous diuretic of potential value for the treatment of water retention and hyponatremia.

\subsubsection{Effects of LIT01-196 on AVP-Induced Antidiuresis in an Experimental Model of Hyponatremia}

In rats, the continuous s.c. infusion of AVP (30 ng/h) for four days, together with a semi-liquid diet, led to a decrease in urine output, an increase in urine osmolality and a decrease in plasma sodium levels, which stabilized at about $100 \mathrm{mmol} / \mathrm{l}$ for two to four days after the initiation of infusion.

The administration of LIT01-196 (900 nmol/kg, s.c.) for two days in this rat model of hyponatremia, by re-establishing the "AVP/(apelin + LIT01-196)" balance, inhibited the effects of AVP on urine output and urine osmolality effectively, and induced a progressive correction of plasma sodium levels (86) (Figure 4). In addition, chronic treatment with LIT01-196 is not associated with renal failure or histological alterations of the kidney, and no change in plasma sodium, potassium, and glucose levels is observed in control rats.

As expected from previous work (118), tolvaptan at the same equimolar dose $(900 \mathrm{nmol} / \mathrm{kg})$ also inhibits the antidiuretic effect of AVP. However, increasing the dose of tolvaptan results in an even larger increase in urine output, whereas increasing the dose of LIT01-196 did not. It can, therefore, be hypothesized that activating the ApelinR with a metabolically stable apelin analog, thereby reestablishing the apelin/AVP balance in the $\mathrm{CD}$, rather than blocking the effects of AVP with V2-R antagonists, may result in less severe polyuria and may be better tolerated than V2-R antagonists. Moreover treatment by metabolically stable apelin analogs, may be also useful for the treatment of autosomal dominant polycystic 
A

\section{LIT01-196}

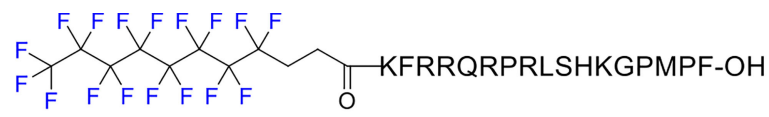

B

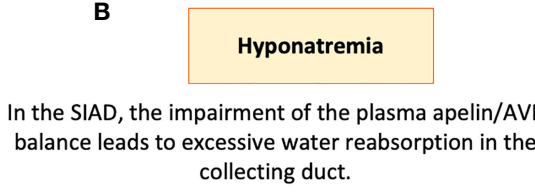
collecting duct.

\section{Plasma sodium \\ correction}

In the SIAD, the impairment of the plasma apelin/AVP $\quad$ The apelin-R agonist, LIT01-196, or the V2-R antagonist, tolvaptan, can both inhibit the antidiuretic effect of AVP by decreasing intracellular cAMP production

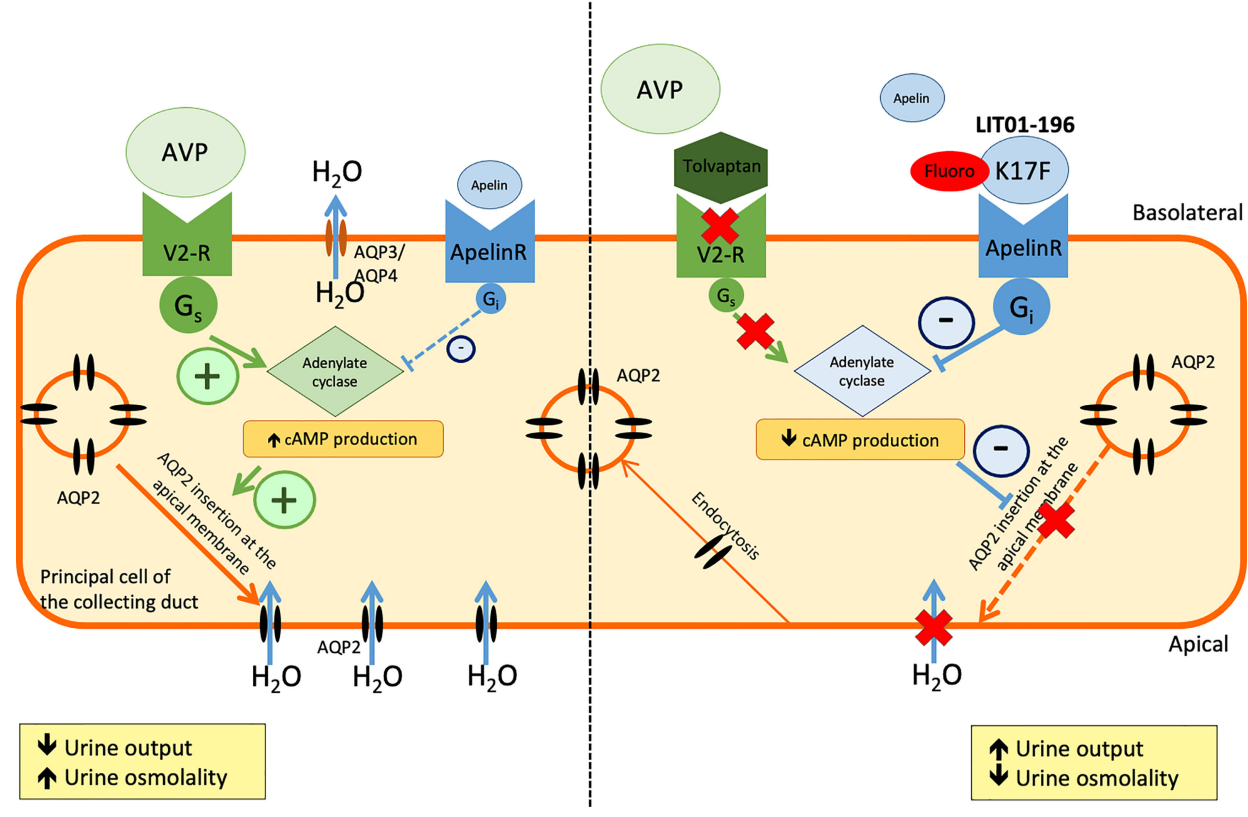

FIGURE 4 | Proposed model of the effects of LIT01-196 on the principal cells of the collecting duct in SIAD. (A) Chemical structure of LIT01-196. (B) Schematic representation of the apelin and vasopressin (AVP). (B) Schematic representation of the apelin and vasopressin (AVP) receptors signaling pathways in the principal cells of the collecting duct (CD). Signaling pathways in the principal cells of the collecting duct (CD). In SIAD, the increase in AVP secretion is inadequate relative to plasma osmolality leading to hyponatremia. Consequently, there is an abnormal apelin/AVP balance in hyponatremic SIAD patients which contributes to water retention. By acting on $\mathrm{V} 2$ receptors (V2-R) present in the principal cells of the $\mathrm{CD}$, the increased AVP levels stimulate cAMP production, leading to the insertion of aquaporin 2 (AQP2) into the apical membrane of $\mathrm{CD}$, resulting in higher levels of water reabsorption $\left(\mathrm{H}_{2} \mathrm{O}\right)$, lower levels of diuresis, and hyponatremia. In SIAD, LIT01-196, by acting on the ApelinR present in the CD, re-establishes the "AVP/(apelin + LIT01-196)" balance and inhibits AVP-induced cAMP production, thereby inhibiting the insertion of AQP2 into the apical membrane of the CD, resulting in the inhibition of water reabsorption by the kidney and an increase in aqueous diuresis. As previously described, tolvaptan, by blocking the action of AVP on the V2-R, induces a similar increase in aqueous diuresis. Figure adapted from Ref. (86) with permission from the copyright holders.

kidney disease (ADPKD) (119) a disorder linked to excessive AVP secretion, since chronic treatment with tolvaptan, although effective, may be associated with intense thirst, polyuria ( $24 \mathrm{~h}$ diuresis around $6 \mathrm{~L} /$ day), nocturia (120) and a rapid plasma sodium concentration correction $(121,122)$. A too rapid plasma sodium correction in chronic hyponatremia can lead to osmotic demyelination, a severe neurological complication (123). Another situation where the apelin analogs would be useful in hyponatremic patients with hepatic insufficiency in whom the use of V2-R antagonists is contraindicated, due to their long-term hepatotoxic effect $(124,125)$.

Another application for metabolically stable apelin analogs could be in the nephrogenic syndrome of inappropriate antidiuresis (NSIAD). Gain-of-function mutations of the V2R are responsible for NSIAD. Patients with NSIAD have reduced free water excretion and concentrated urine despite hyponatremia and low or undetectable circulating AVP levels (126). This was due to substitution in the V2R sequence, of the arginine residue in position 137 by either a leucine or a cysteine (R137L/C) or the phenylalanine in position 229 by a valine (F229V) $(127,128)$. $\mathrm{R} 137 \mathrm{C}$ was found to be the most frequent mutation. In absence of AVP, both R137L and R137C mutants displayed constitutive cAMP production and a high rate of arrestin-dependent constitutive internalization $(128,129)$. In vitro studies have shown that tolvaptan and satavaptan do not reduce constitutive increase of cAMP levels in R137L/C variants $(130,131)$. In line with in vitro data, a patient carrying the $\mathrm{R} 137 \mathrm{~L}$ did not respond to the administration of these V2R antagonists (132). The use of a metabolically stable apelin analog in the management of NSIAD could be of potential therapeutic interest since by activating the ApelinR, it will reduces cAMP production, reducing the insertion of 
AQP-2 at the apical membrane of collecting duct cells, thus decreasing water reabsorption and increasing urine output $(84,86)$.

This remains to be evaluated in further experimental studies and clinical trials. The various physiological effects associated with ApelinR activation result from the activation of different signaling pathways. The development of biased metabolically stable apelin-17 analogs targeting only the Gi signaling pathway might, therefore, increase their specificity of action for water metabolism.

\section{CARDIOVASCULAR ACTIONS OF APELIN}

Apelin has a wide range of physiological effects. Apelin plays a role in the cardiovascular system, acting on the endothelium of human mammary artery, human splanchnic arteries or rat glomerular arterioles and inducing vasodilation by increasing nitric oxide $(\mathrm{NO})(35,133,134)$. In contrast, apelin exerts a direct vasoconstrictive effect on vascular smooth muscle cells in endothelium-denuded arteries (14, 135-137). Several in vivo studies have reported that different apelin analogs or apelinomimetics induce a rapid and dose-dependent reduction in BP, always mediated by $\mathrm{NO}(22,29,36,46,133,138)$. This vasodilatory effect has also been observed in humans, where infusions of apelin-13 and apelin-36 result in a dose-dependent and NO-dependent arteriolar vasodilation in the forearm (106, 139). In healthy volunteers, apelin-13 induces a decrease in arterial BP, peripheral vascular resistance and induced a slight increase in heart rate which was probably a compensatory effect to the decrease in BP (102).

At the cardiac level, apelin is the most potent endogenous positive inotropic peptide discovered to date (140-142). Apelin reduces cardiac preload and afterload (143). Apelin also increases conduction velocity in cardiomyocytes and induces a shortening of action potential in atrial myocytes $(144,145)$. Apelin potently inhibited AngII-induced atrial fibrosis and subsequent vulnerability to atrial fibrillation induction (146). Administration of apelin or a small molecule apelinR agonist increases cardiac output in vivo in rodents $(111,147)$. Administration of apelin or apelin analogs in rodents post-myocardial infarction improved functional recovery and reduced infarct size, most likely due to increase NO production and angiogenesis (110, 148-150). Administration of apelin for 2 weeks after aortic banding prevented cardiac remodeling by inhibiting myocyte hypertrophy, cardiac fibrosis and ventricular dysfunction (151). In heart failure patients, acute administration of apelin, by intravenous route, increases cardiac output and left ventricular ejection fraction while reducing blood pressure and vascular resistance $(102,152)$. Apelin-knockout mice develop progressive impairment of cardiac contractility associated with systolic dysfunction in the absence of histological abnormalities. Importantly, pressure overload- induced heart failure is also more severe in apelin-deficient mice (153). Moreover, infusion of apelin using osmotic minipumps for 2 weeks in apelin-deficient mice restored the impaired cardiac function to that of wild-type mice (154).
Therefore, the use of ApelinR agonists may constitute a new therapeutic approach for the treatment of heart failure by increasing aqueous diuresis and cardiac contractility while decreasing vascular resistance.

\section{CONCLUSION AND PERSPECTIVES}

The identification of apelin as the endogenous ligand of the orphan receptor APJ constituted an important step in basic research, with clinical implications. In animal models, experimental data have shown that the central injection of apelin into lactating rats inhibits the phasic electrical activity of AVP neurons, reduces plasma AVP levels, and increases aqueous diuresis. In the kidney, apelin increases aqueous diuresis by increasing renal blood flow and by counteracting the antidiuretic effect of AVP in the kidney at the tubular level. Following water deprivation or dehydration, in humans and rodents, AVP and apelin are conversely regulated, to facilitate systemic AVP release and to prevent additional water loss in the kidney. Moreover following water loading, AVP and apelin display an opposite pattern of regulation to facilitate systemic apelin release and increase aqueous diuresis to re-establish a water balance face to water overload. The available data show that AVP and apelin play a crucial role in maintaining body fluid homeostasis in humans and rodents. SIAD patients have an altered apelin-to-copeptin balance, contributing to the water metabolism defect. Apelin- $\mathrm{R}$ activation by a metabolically stable apelin-17 analog, LIT01-196, may constitute a promising therapeutic approach for the treatment of SIAD, by inhibiting the antidiuretic effect of AVP, increasing urine output, decreasing urine osmolality, moderately enhancing water intake, and progressively correcting hyponatremia.

\section{AUTHOR NOTES}

All appropriate permissions have been obtained from the copyright holders of Figures 1-4, which have been adapted and reproduced for this manuscript.

\section{AUTHOR CONTRIBUTIONS}

All authors listed have made substantial, direct, and intellectual contribution to the work and approved it for publication.

\section{FUNDING}

These studies were supported by INSERM [Annual dotation], including the financial support for Proof of Concept, CoPoc Apelinatremia 2015-2017 from INSERM Transfert, the CNRS, the College de France, the Agence Nationale de la Recherche ANR-16-CE18-0030, FluoroPEP) and the Federation Française de Cardiologie. PEGS was supported by a fellowship from the Fondation pour la Recherche Médicale, grant number "PBR201810007643". AF was supported by the fellowship from INSERM (Poste d'Accueil pour Hospitaliers). 


\section{REFERENCES}

1. O'Dowd BF, Heiber M, Chan A, Heng HH, Tsui LC, Kennedy JL, et al. A Human Gene That Shows Identity With the Gene Encoding the Angiotensin Receptor Is Located on Chromosome 11. Gene (1993) 136:355-60. doi: 10.1016/0378-1119(93)90495-o

2. De Mota N, Lenkei Z, Llorens-Cortès C. Cloning, Pharmacological Characterization and Brain Distribution of the Rat Apelin Receptor. Neuroendocrinology (2000) 72:400-7. doi: 10.1159/000054609

3. O'Carroll AM, Selby TL, Palkovits M, Lolait SJ. Distribution of mRNA Encoding B78/apj, the Rat Homologue of the Human APJ Receptor, and Its Endogenous Ligand Apelin in Brain and Peripheral Tissues. Biochim Biophys Acta (2000) 1492:72-80. doi: 10.1016/s0167-4781(00)00072-5

4. Hosoya M, Kawamata Y, Fukusumi S, Fujii R, Habata Y, Hinuma S, et al. Molecular and Functional Characteristics of APJ. Tissue Distribution of mRNA and Interaction With the Endogenous Ligand Apelin. J Biol Chem (2000) 275:21061-7. doi: 10.1074/jbc.M908417199

5. Devic E, Rizzoti K, Bodin S, Knibiehler B, Audigier Y. Amino Acid Sequence and Embryonic Expression of Msr/Apj, the Mouse Homolog of Xenopus XMsr and Human APJ. Mech Dev (1999) 84:199-203. doi: 10.1016/s09254773(99)00081-7

6. Tatemoto K, Hosoya M, Habata Y, Fujii R, Kakegawa T, Zou MX, et al. Isolation and Characterization of a Novel Endogenous Peptide Ligand for the Human APJ Receptor. Biochem Biophys Res Commun (1998) 251:471-6. doi: 10.1006/bbrc.1998.9489

7. Galanth C, Hus-Citharel A, Li B, Llorens-Cortès C. Apelin in the Control of Body Fluid Homeostasis and Cardiovascular Functions. Curr Pharm Des (2012) 18:789-98. doi: 10.2174/138161212799277770

8. Lee DK, Cheng R, Nguyen T, Fan T, Kariyawasam AP, Liu Y, et al. Characterization of Apelin, the Ligand for the APJ Receptor. J Neurochem (2000) 74:34-41. doi: 10.1046/j.1471-4159.2000.0740034.x

9. Habata Y, Fujii R, Hosoya M, Fukusumi S, Kawamata Y, Hinuma S, et al. Apelin, the Natural Ligand of the Orphan Receptor APJ, is Abundantly Secreted in the Colostrum. Biochim Biophys Acta (1999) 1452:25-35. doi: 10.1016/s0167-4889(99)00114-7

10. Kawamata Y, Habata Y, Fukusumi S, Hosoya M, Fujii R, Hinuma S, et al. Molecular Properties of Apelin: Tissue Distribution and Receptor Binding. Biochim Biophys Acta (2001) 1538:162-71. doi: 10.1016/s0167-4889(00) 00143-9

11. De Mota N, Reaux-Le Goazigo A, El Messari S, Chartrel N, Roesch D, Dujardin C, et al. Apelin, a Potent Diuretic Neuropeptide Counteracting Vasopressin Actions Through Inhibition of Vasopressin Neuron Activity and Vasopressin Release. Proc Natl Acad Sci USA (2004) 101:10464-9. doi: 10.1073/pnas.0403518101

12. Azizi M, Iturrioz X, Blanchard A, Peyrard S, De Mota N, Chartrel N, et al. Reciprocal Regulation of Plasma Apelin and Vasopressin by Osmotic Stimuli. J Am Soc Nephrol (2008) 19:1015-24. doi: 10.1681/ASN.2007070816

13. Shin K, Pandey A, Liu X-Q, Anini Y, Rainey JK. Preferential Apelin-13 Production by the Proprotein Convertase PCSK3 is Implicated in Obesity. FEBS Open Bio (2013) 3:328-33. doi: 10.1016/j.fob.2013.08.001

14. Maguire JJ, Kleinz MJ, Pitkin SL, Davenport AP. [Pyr1]apelin-13 Identified as the Predominant Apelin Isoform in the Human Heart: Vasoactive Mechanisms and Inotropic Action in Disease. Hypertension (2009) 54:598-604. doi: 10.1161/HYPERTENSIONAHA.109.134619

15. Vickers C, Hales P, Kaushik V, Dick L, Gavin J, Tang J, et al. Hydrolysis of Biological Peptides by Human Angiotensin-Converting Enzyme-Related Carboxypeptidase. J Biol Chem (2002) 277:14838-43. doi: 10.1074/ jbc.M200581200

16. Wang W, McKinnie SMK, Farhan M, Paul M, McDonald T, McLean B, et al. Angiotensin-Converting Enzyme 2 Metabolizes and Partially Inactivates PyrApelin-13 and Apelin-17: Physiological Effects in the Cardiovascular System. Hypertension (2016) 68:365-77. doi: 10.1161/HYPERTENSIONAHA.115.06892

17. McKinnie SMK, Fischer C, Tran KMH, Wang W, Mosquera F, Oudit GY, et al. The Metalloprotease Neprilysin Degrades and Inactivates Apelin Peptides. Chembiochem (2016) 17:1495-8. doi: 10.1002/cbic.201600244

18. McKinnie SMK, Wang W, Fischer C, McDonald T, Kalin KR, Iturrioz X, et al. Synthetic Modification Within the "RPRL" Region of Apelin Peptides: Impact on Cardiovascular Activity and Stability to Neprilysin and Plasma
Degradation. J Med Chem (2017) 60:6408-27. doi: 10.1021/ acs.jmedchem.7b00723

19. Chng SC, Ho L, Tian J, Reversade B. ELABELA: A Hormone Essential for Heart Development Signals via the Apelin Receptor. Dev Cell (2013) 27:67280. doi: 10.1016/j.devcel.2013.11.002

20. Pauli A, Norris ML, Valen E, Chew G-L, Gagnon JA, Zimmerman S, et al. Toddler: An Embryonic Signal That Promotes Cell Movement via Apelin Receptors. Science (2014) 343:1248636. doi: 10.1126/science.1248636

21. Read C, Nyimanu D, Williams TL, Huggins DJ, Sulentic P, Macrae RGC, et al. International Union of Basic and Clinical Pharmacology. CVII. Structure and Pharmacology of the Apelin Receptor With a Recommendation That Elabela/Toddler Is a Second Endogenous Peptide Ligand. Pharmacol Rev (2019) 71:467-502. doi: 10.1124/pr.119.017533

22. Yang P, Read C, Kuc RE, Buonincontri G, Southwood M, Torella R, et al. Elabela/Toddler Is an Endogenous Agonist of the Apelin APJ Receptor in the Adult Cardiovascular System, and Exogenous Administration of the Peptide Compensates for the Downregulation of Its Expression in Pulmonary Arterial Hypertension. Circulation (2017) 135:1160-73. doi: 10.1161/ CIRCULATIONAHA.116.023218

23. Soulet F, Bodineau C, Hooks KB, Descarpentrie J, Alves I, Dubreuil M, et al. ELA/APELA Precursor Cleaved by Furin Displays Tumor Suppressor Function in Renal Cell Carcinoma Through Mtorc1 Activation. JCI Insight (2020) 5:129070. doi: 10.1172/jci.insight.129070

24. Couvineau P, Llorens-Cortes C, Iturrioz X. Elabela/Toddler and Apelin Bind Differently to the Apelin Receptor. FASEB J (2020) 34:7989-8000. doi: 10.1096/fj.201903029R

25. Chen H, Wang L, Wang W, Cheng C, Zhang Y, Zhou Y, et al. ELABELA and an ELABELA Fragment Protect Against AKI. J Am Soc Nephrol (2017) 28:2694-707. doi: 10.1681/ASN.2016111210

26. Medhurst AD, Jennings CA, Robbins MJ, Davis RP, Ellis C, Winborn KY, et al. Pharmacological and Immunohistochemical Characterization of the APJ Receptor and its Endogenous Ligand Apelin. J Neurochem (2003) 84:1162-72. doi: 10.1046/j.1471-4159.2003.01587.x

27. Iturrioz X, Gerbier R, Leroux V, Alvear-Perez R, Maigret B, Llorens-Cortes C. By Interacting With the C-Terminal Phe of Apelin, Phe255 and Trp259 in Helix VI of the Apelin Receptor Are Critical for Internalization. J Biol Chem (2010) 285:32627-37. doi: 10.1074/jbc.M110.127167

28. Gerbier R, Leroux V, Couvineau P, Alvear-Perez R, Maigret B, LlorensCortes C, et al. New Structural Insights Into the Apelin Receptor: Identification of Key Residues for Apelin Binding. FASEB J (2015) 29:31422. doi: $10.1096 / f$ f. $14-256339$

29. El Messari S, Iturrioz X, Fassot C, De Mota N, Roesch D, Llorens-Cortes C. Functional Dissociation of Apelin Receptor Signaling and Endocytosis: Implications for the Effects of Apelin on Arterial Blood Pressure. J Neurochem (2004) 90:1290-301. doi: 10.1111/j.1471-4159.2004.02591.x

30. Masri B, Morin N, Pedebernade L, Knibiehler B, Audigier Y. The Apelin Receptor is Coupled to Gi1 or Gi2 Protein and Is Differentially Desensitized by Apelin Fragments. J Biol Chem (2006) 281:18317-26. doi: 10.1074/ jbc.M600606200

31. Bai B, Tang J, Liu H, Chen J, Li Y, Song W. Apelin-13 Induces ERK1/2 But Not P38 MAPK Activation Through Coupling of the Human Apelin Receptor to the Gi2 Pathway. Acta Biochim Biophys Sin (Shanghai) (2008) 40:311-8. doi: 10.1111/j.1745-7270.2008.00403.x

32. Choe W, Albright A, Sulcove J, Jaffer S, Hesselgesser J, Lavi E, et al. Functional Expression of the Seven-Transmembrane HIV-1 Co-Receptor APJ in Neural Cells. J Neurovirol (2000) 6(Suppl 1):S61-69.

33. Zhou N, Fan X, Mukhtar M, Fang J, Patel CA, DuBois GC, et al. Cell-Cell Fusion and Internalization of the CNS-Based, HIV-1 Co-Receptor, APJ. Virology (2003) 307:22-36. doi: 10.1016/s0042-6822(02)00021-1

34. Zhou N, Zhang X, Fan X, Argyris E, Fang J, Acheampong E, et al. The NTerminal Domain of APJ, a CNS-Based Coreceptor for HIV-1, is Essential for Its Receptor Function and Coreceptor Activity. Virology (2003) 317:8494. doi: $10.1016 /$ j.virol.2003.08.026

35. Hus-Citharel A, Bouby N, Frugière A, Bodineau L, Gasc J-M, Llorens-Cortes C. Effect of Apelin on Glomerular Hemodynamic Function in the Rat Kidney. Kidney Int (2008) 74:486-94. doi: 10.1038/ki.2008.199

36. Tatemoto K, Takayama K, Zou M-X, Kumaki I, Zhang W, Kumano K, et al. The Novel Peptide Apelin Lowers Blood Pressure via a Nitric Oxide- 
Dependent Mechanism. Regul Peptides (2001) 99:87-92. doi: 10.1016/S01670115(01)00236-1

37. Reaux A, De Mota N, Skultetyova I, Lenkei Z, El Messari S, Gallatz K, et al. Physiological Role of a Novel Neuropeptide, Apelin, and Its Receptor in the Rat Brain. J Neurochem (2001) 77:1085-96. doi: 10.1046/j.14714159.2001.00320.x

38. Gerbier R, Alvear-Perez R, Margathe J-F, Flahault A, Couvineau P, Gao J, et al. Development of Original Metabolically Stable Apelin-17 Analogs With Diuretic and Cardiovascular Effects. FASEB J (2017) 31:687-700. doi: 10.1096/fj.201600784R

39. Masri B, Lahlou H, Mazarguil H, Knibiehler B, Audigier Y. Apelin (65-77) Activates Extracellular Signal-Regulated Kinases via a PTX-Sensitive G Protein. Biochem Biophys Res Commun (2002) 290:539-45. doi: 10.1006/ bbrc.2001.6230

40. Eyries M, Siegfried G, Ciumas M, Montagne K, Agrapart M, Lebrin F, et al. Hypoxia-Induced Apelin Expression Regulates Endothelial Cell Proliferation and Regenerative Angiogenesis. Circ Res (2008) 103:432-40. doi: 10.1161/CIRCRESAHA.108.179333

41. D’Aniello C, Lonardo E, Iaconis S, Guardiola O, Liguoro AM, Liguori GL, et al. Minchiotti G. G Protein-Coupled Receptor APJ and Its Ligand Apelin Act Downstream of Cripto to Specify Embryonic Stem Cells Toward the Cardiac Lineage Through Extracellular Signal-Regulated Kinase/P70s6 Kinase Signaling Pathway. Circ Res (2009) 105:231-8. doi: 10.1161/ CIRCRESAHA.109.201186

42. Evans NA, Groarke DA, Warrack J, Greenwood CJ, Dodgson K, Milligan G, et al. Visualizing Differences in Ligand-Induced Beta-Arrestin-GFP Interactions and Trafficking Between Three Recently Characterized G Protein-Coupled Receptors. J Neurochem (2001) 77:476-85. doi: 10.1046/ j.1471-4159.2001.00269.x

43. Chen X, Bai B, Tian Y, Du H, Chen J. Identification of Serine 348 on the Apelin Receptor as a Novel Regulatory Phosphorylation Site in Apelin-13Induced G Protein-Independent Biased Signaling. J Biol Chem (2014) 289:31173-87. doi: 10.1074/jbc.M114.574020

44. Besserer-Offroy É, Bérubé P, Côté J, Murza A, Longpré J-M, Dumaine R, et al. The Hypotensive Effect of Activated Apelin Receptor is Correlated With $\beta$-Arrestin Recruitment. Pharmacol Res (2018) 131:7-16. doi: 10.1016/ j.phrs.2018.02.032

45. Ceraudo E, Galanth C, Carpentier E, Banegas-Font I, Schonegge A-M, Alvear-Perez R, et al. Biased Signaling Favoring Gi Over $\beta$-Arrestin Promoted by an Apelin Fragment Lacking the C-Terminal Phenylalanine. J Biol Chem (2014) 289:24599-610. doi: 10.1074/jbc.M113.541698

46. Lee DK, Saldivia VR, Nguyen T, Cheng R, George SR, O’Dowd BF. Modification of the Terminal Residue of Apelin-13 Antagonizes Its Hypotensive Action. Endocrinology (2005) 146:231-6. doi: 10.1210/ en.2004-0359

47. Lee DK, Ferguson SSG, George SR, O'Dowd BF. The Fate of the Internalized Apelin Receptor is Determined by Different Isoforms of Apelin Mediating Differential Interaction With Beta-Arrestin. Biochem Biophys Res Commun (2010) 395:185-9. doi: 10.1016/j.bbrc.2010.03.151

48. Chun HJ, Ali ZA, Kojima Y, Kundu RK, Sheikh AY, Agrawal R, et al. Apelin Signaling Antagonizes Ang II Effects in Mouse Models of Atherosclerosis. J Clin Invest (2008) 118:3343-54. doi: 10.1172/JCI34871

49. Sun X, Iida S, Yoshikawa A, Senbonmatsu R, Imanaka K, Maruyama K, et al. Non-Activated APJ Suppresses the Angiotensin II Type 1 Receptor, Whereas Apelin-Activated APJ Acts Conversely. Hypertens Res (2011) 34:701-6. doi: 10.1038/hr.2011.19

50. Siddiquee K, Hampton J, McAnally D, May L, Smith L. The Apelin Receptor Inhibits the Angiotensin II Type 1 Receptor via Allosteric Trans-Inhibition. Br J Pharmacol (2013) 168:1104-17. doi: 10.1111/j.1476-5381.2012.02192.x

51. Li Y, Chen J, Bai B, Du H, Liu Y, Liu H. Heterodimerization of Human Apelin and Kappa Opioid Receptors: Roles in Signal Transduction. Cell Signal (2012) 24:991-1001. doi: 10.1016/j.cellsig.2011.12.012

52. Bai B, Liu L, Zhang N, Wang C, Jiang Y, Chen J. Heterodimerization of Human Apelin and Bradykinin 1 Receptors: Novel Signal Transduction Characteristics. Cell Signal (2014) 26:1549-59. doi: 10.1016/j.cellsig.2014.03.022

53. Pope GR, Roberts EM, Lolait SJ, O'Carroll A-M. Central and Peripheral Apelin Receptor Distribution in the Mouse: Species Differences With Rat. Peptides (2012) 33:139-48. doi: 10.1016/j.peptides.2011.12.005
54. Reaux A, Gallatz K, Palkovits M, Llorens-Cortes C. Distribution of ApelinSynthesizing Neurons in the Adult Rat Brain. Neuroscience (2002) 113:65362. doi: 10.1016/S0306-4522(02)00192-6

55. Brailoiu GC, Dun SL, Yang J, Ohsawa M, Chang JK, Dun NJ. ApelinImmunoreactivity in the Rat Hypothalamus and Pituitary. Neurosci Lett (2002) 327:193-7. doi: 10.1016/S0304-3940(02)00411-1

56. Reaux-Le Goazigo A, Morinville A, Burlet A, Llorens-Cortes C, Beaudet A. Dehydration-Induced Cross-Regulation of Apelin and Vasopressin Immunoreactivity Levels in Magnocellular Hypothalamic Neurons. Endocrinology (2004) 145:4392-400. doi: 10.1210/en.2004-0384

57. Bodineau L, Taveau C, Lê Quan Sang H-H, Osterstock G, Queguiner I, Moos F, et al. Data Supporting a New Physiological Role for Brain Apelin in the Regulation of Hypothalamic Oxytocin Neurons in Lactating Rats. Endocrinology (2011) 152:3492-503. doi: 10.1210/en.2011-0206

58. Buggy J, Fink GD, Johnson AK, Brody MJ. Prevention of the Development of Renal Hypertension by Anteroventral Third Ventricular Tissue Lesions. Circ Res (1977) 40:I110-117.

59. Johnson AK, Cunningham JT, Thunhorst RL. Integrative Role of the Lamina Terminalis in the Regulation of Cardiovascular and Body Fluid Homeostasis. Clin Exp Pharmacol Physiol (1996) 23:183-91. doi: 10.1111/j.14401681.1996.tb02594.x

60. O'Carroll A-M, Lolait SJ. Regulation of Rat APJ Receptor Messenger Ribonucleic Acid Expression in Magnocellular Neurones of the Paraventricular and Supraopric Nuclei by Osmotic Stimuli. J Neuroendocrinol (2003) 15:661-6. doi: 10.1046/j.1365-2826.2003.01044.x

61. Hurbin A, Boissin-Agasse L, Orcel H, Rabié A, Joux N, Desarménien MG, et al. The V1a and V1b, But Not V2, Vasopressin Receptor Genes Are Expressed in the Supraoptic Nucleus of the Rat Hypothalamus, and the Transcripts Are Essentially Colocalized in the Vasopressinergic Magnocellular Neurons. Endocrinology (1998) 139:4701-7. doi: 10.1210/endo.139.11.6320

62. Kleinz MJ, Skepper JN, Davenport AP. Immunocytochemical Localisation of the Apelin Receptor, APJ, to Human Cardiomyocytes, Vascular Smooth Muscle and Endothelial Cells. Regul Pept (2005) 126:233-40. doi: 10.1016/ j.regpep.2004.10.019

63. Ripoll E, Pluvinet R, Torras J, Olivar R, Vidal A, Franquesa M, et al. In Vivo Therapeutic Efficacy of Intra-Renal CD40 Silencing in a Model of Humoral Acute Rejection. Gene Ther (2011) 18:945-52. doi: 10.1038/gt.2011.39

64. O'Carroll A-M, Salih S, Griffiths PR, Bijabhai A, Knepper MA, Lolait SJ. Expression and Functional Implications of the Renal Apelinergic System in Rodents. PloS One (2017) 12:e0183094. doi: 10.1371/journal.pone.0183094

65. Xu C, Wang F, Chen Y, Xie S, Sng D, Reversade B, et al. ELABELA Antagonizes Intrarenal Renin-Angiotensin System to Lower Blood Pressure and Protects Against Renal Injury. Am J Physiol Renal Physiol (2020) 318:F1122-35. doi: 10.1152/ajprenal.00606.2019

66. Ostrowski NL, Lolait SJ, Bradley DJ, O'Carroll AM, Brownstein MJ, Young WS. Distribution of V1a and V2 Vasopressin Receptor Messenger Ribonucleic Acids in Rat Liver, Kidney, Pituitary and Brain. Endocrinology (1992) 131:533-5. doi: 10.1210/endo.131.1.1535312

67. Sekerci R, Acar N, Tepekoy F, Ustunel I, Keles-Celik N. Apelin/APJ Expression in the Heart and Kidneys of Hypertensive Rats. Acta Histochemica (2018) 120:196-204. doi: 10.1016/j.acthis.2018.01.007

68. Manning M, Lowbridge J, Haldar J, Sawyer WH. Design of Neurohypophyseal Peptides That Exhibit Selective Agonistic and Antagonistic Properties. Fed Proc (1977) 36:1848-52.

69. Brownstein MJ, Russell JT, Gainer H. Synthesis, Transport, and Release of Posterior Pituitary Hormones. Science (1980) 207:373-8. doi: 10.1126/science.6153132

70. Couvineau P, de Almeida H, Maigret B, Llorens-Cortes C, Iturrioz X. Involvement of Arginine 878 Together With Ca2+ in Mouse Aminopeptidase A Substrate Specificity for N-Terminal Acidic AminoAcid Residues. PloS One (2017) 12:e0184237. doi: 10.1371/ journal.pone. 0184237

71. Gouzènes L, Desarménien MG, Hussy N, Richard P, Moos FC. Vasopressin Regularizes the Phasic Firing Pattern of Rat Hypothalamic Magnocellular Vasopressin Neurons. J Neurosci (1998) 18:1879-85. doi: 10.1523/ JNEUROSCI.18-05-01879.1998

72. Poulain DA, Wakerley JB, Dyball RE. Electrophysiological Differentiation of Oxytocin- and Vasopressin-Secreting Neurones. Proc R Soc Lond B Biol Sci (1977) 196:367-84. doi: 10.1098/rspb.1977.0046 
73. Gimpl G, Fahrenholz F. The Oxytocin Receptor System: Structure, Function, and Regulation. Physiol Rev (2001) 81:629-83. doi: 10.1152/ physrev.2001.81.2.629

74. Llorens-Cortes C, Moos F. Apelin and Vasopressin: Two Work Better Than One. J Neuroendocrinol (2012) 24:1085-6. doi: 10.1111/j.1365-2826. 2012.02316.x

75. Kadekaro M, Summy-Long JY, Freeman S, Harris JS, Terrell ML, Eisenberg HM. Cerebral Metabolic Responses and Vasopressin and Oxytocin Secretions During Progressive Water Deprivation in Rats. Am J Physiol (1992) 262:R310-17. doi: 10.1152/ajpregu.1992.262.2.R310

76. Hogarty DC, Speakman EA, Puig V, Phillips MI. The Role of Angiotensin, AT1 and AT2 Receptors in the Pressor, Drinking and Vasopressin Responses to Central Angiotensin. Brain Res (1992) 586:289-94. doi: 10.1016/0006-8993(92)91638-u

77. Reaux-Le Goazigo A, Alvear-Perez R, Zizzari P, Epelbaum J, Bluet-Pajot M$\mathrm{T}$, Llorens-Cortes C. Cellular Localization of Apelin and Its Receptor in the Anterior Pituitary: Evidence for a Direct Stimulatory Action of Apelin on ACTH Release. Am J Physiol Endocrinol Metab (2007) 292:E7-15. doi: 10.1152/ajpendo.00521.2005

78. Gallo-Payet N. 60 YEARS OF POMC: Adrenal and Extra-Adrenal Functions of ACTH. J Mol Endocrinol (2016) 56:T135-156. doi: 10.1530/JME-15-0257

79. Raff H. Glucocorticoid Inhibition of Neurohypophysial Vasopressin Secretion. Am J Physiol (1987) 252:R635-644. doi: 10.1152/ajpregu.1987.252.4.R635

80. Nielsen S, Chou CL, Marples D, Christensen EI, Kishore BK, Knepper MA. Vasopressin Increases Water Permeability of Kidney Collecting Duct by Inducing Translocation of Aquaporin-CD Water Channels to Plasma Membrane. Proc Natl Acad Sci USA (1995) 92:1013-7. doi: 10.1073/ pnas.92.4.1013

81. Sands JM, Naruse M, Baum M, Jo I, Hebert SC, Brown EM, et al. Apical Extracellular Calcium/Polyvalent Cation-Sensing Receptor Regulates Vasopressin-Elicited Water Permeability in Rat Kidney Inner Medullary Collecting Duct. J Clin Invest (1997) 99:1399-405. doi: 10.1172/JCI119299

82. Murza A, Sainsily X, Coquerel D, Côté J, Marx P, Besserer-Offroy É, et al. Discovery and Structure-Activity Relationship of a Bioactive Fragment of ELABELA That Modulates Vascular and Cardiac Functions. J Med Chem (2016) 59:2962-72. doi: 10.1021/acs.jmedchem.5b01549

83. Hus-Citharel A, Bodineau L, Frugière A, Joubert F, Bouby N, Llorens-Cortes C. Apelin Counteracts Vasopressin-Induced Water Reabsorption via Cross Talk Between Apelin and Vasopressin Receptor Signaling Pathways in the Rat Collecting Duct. Endocrinology (2014) 155:4483-93. doi: 10.1210/ en.2014-1257

84. Boulkeroua C, Ayari H, Khalfaoui T, Lafrance M, Besserer-Offroy É, Ekindi $\mathrm{N}$, et al. Apelin-13 Regulates Vasopressin-Induced Aquaporin-2 Expression and Trafficking in Kidney Collecting Duct Cells. Cell Physiol Biochem (2019) 53:687-700. doi: 10.33594/000000165

85. Chen Y, Xu C, Hu J, Deng M, Qiu Q, Mo S, et al. Diuretic Action of Apelin13 Mediated by Inhibiting cAMP/PKA/sPRR Pathway. Front Physiol (2021) 12:642274. doi: 10.3389/fphys.2021.642274

86. Flahault A, Girault-Sotias P-E, Keck M, Alvear-Perez R, De Mota N, Estéoulle L, et al. A Metabolically Stable Apelin-17 Analog Decreases AVP-Induced Antidiuresis and Improves Hyponatremia. Nat Commun (2021) 12:305. doi: 10.1038/s41467-020-20560-y

87. Deng C, Chen H, Yang N, Feng Y, Hsueh AJW. Apela Regulates Fluid Homeostasis by Binding to the APJ Receptor to Activate Gi Signaling*. J Biol Chem (2015) 290:18261-8. doi: 10.1074/jbc.M115.648238

88. Tang C, Zelenak C, Völkl J, Eichenmüller M, Regel I, Fröhlich H, et al. Hydration-Sensitive Gene Expression in Brain. Cell Physiol Biochem (2011) 27:757-68. doi: 10.1159/000330084

89. Roberts EM, Newson MJF, Pope GR, Landgraf R, Lolait SJ, O'Carroll A-M. Abnormal Fluid Homeostasis in Apelin Receptor Knockout Mice. J Endocrinol (2009) 202:453-62. doi: 10.1677/JOE-09-0134

90. Roberts EM, Pope GR, Newson MJF, Landgraf R, Lolait SJ, O'Carroll A-M. Stimulus-Specific Neuroendocrine Responses to Osmotic Challenges in Apelin Receptor Knockout Mice. J Neuroendocrinol (2010) 22:301-8. doi: 10.1111/j.1365-2826.2010.01968.x

91. Coquerel D, Chagnon F, Sainsily X, Dumont L, Murza A, Côté J, et al. ELABELA Improves Cardio-Renal Outcome in Fatal Experimental Septic Shock. Crit Care Med (2017) 45:e1139-48. doi: 10.1097/CCM.0000000000002639
92. Zingg HH, Lefebvre D, Almazan G. Regulation of Vasopressin Gene Expression in Rat Hypothalamic Neurons. Response to Osmotic Stimulation. J Biol Chem (1986) 261:12956-9. doi: 10.1016/S0021-9258 (18)69255-5

93. Ellison DH, Berl T. Clinical Practice. The Syndrome of Inappropriate Antidiuresis. N Engl J Med (2007) 356:2064-72. doi: 10.1056/ NEJMcp066837

94. Kim WR, Biggins SW, Kremers WK, Wiesner RH, Kamath PS, Benson JT, et al. Hyponatremia and Mortality Among Patients on the Liver-Transplant Waiting List. N Engl J Med (2008) 359:1018-26. doi: 10.1056/ NEJMoa0801209

95. Waikar SS, Mount DB, Curhan GC. Mortality After Hospitalization With Mild, Moderate, and Severe Hyponatremia. Am J Med (2009) 122:857-65. doi: 10.1016/j.amjmed.2009.01.027

96. Kovesdy CP, Lott EH, Lu JL, Malakauskas SM, Ma JZ, Molnar MZ, et al. Hyponatremia, Hypernatremia, and Mortality in Patients With Chronic Kidney Disease With and Without Congestive Heart Failure. Circulation (2012) 125:677-84. doi: 10.1161/CIRCULATIONAHA. 111.065391

97. Peri A. Management of Hyponatremia: Causes, Clinical Aspects, Differential Diagnosis and Treatment. Expert Rev Endocrinol Metab (2019) 14:13-21. doi: $10.1080 / 17446651.2019 .1556095$

98. Verbalis JG, Goldsmith SR, Greenberg A, Korzelius C, Schrier RW, Sterns $\mathrm{RH}$, et al. Diagnosis, Evaluation, and Treatment of Hyponatremia: Expert Panel Recommendations. Am J Med (2013) 126:S1-42. doi: 10.1016/ j.amjmed.2013.07.006

99. Verbalis JG. Euvolemic Hyponatremia Secondary to the Syndrome of Inappropriate Antidiuresis. Front Horm Res (2019) 52:61-79. doi: $10.1159 / 000493238$

100. Blanchard A, Steichen O, De Mota N, Curis E, Gauci C, Frank M, et al. An Abnormal Apelin/Vasopressin Balance may Contribute to Water Retention in Patients With the Syndrome of Inappropriate Antidiuretic Hormone (SIADH) and Heart Failure. J Clin Endocrinol Metab (2013) 98:2084-9. doi: 10.1210/jc.2012-3794

101. Murza A, Belleville K, Longpré J-M, Sarret P, Marsault É. Stability and Degradation Patterns of Chemically Modified Analogs of Apelin-13 in Plasma and Cerebrospinal Fluid. Biopolymers (2014) 102:297-303. doi: 10.1002/bip.22498

102. Japp AG, Cruden NL, Barnes G, van Gemeren N, Mathews J, Adamson J, et al. Acute Cardiovascular Effects of Apelin in Humans: Potential Role in Patients With Chronic Heart Failure. Circulation (2010) 121:1818-27. doi: 10.1161/CIRCULATIONAHA.109.911339

103. Trân K, Van Den Hauwe R, Sainsily X, Couvineau P, Côté J, Simard L, et al. Constraining the Side Chain of C-Terminal Amino Acids in Apelin-13 Greatly Increases Affinity, Modulates Signaling, and Improves the Pharmacokinetic Profile. J Med Chem (2021) 64:5345-64. doi: 10.1021/ acs.jmedchem.0c01941

104. Read C, Fitzpatrick CM, Yang P, Kuc RE, Maguire JJ, Glen RC, et al. Cardiac Action of the First G Protein Biased Small Molecule Apelin Agonist. Biochem Pharmacol (2016) 116:63-72. doi: 10.1016/j.bcp.2016.07.018

105. Murza A, Besserer-Offroy É, Côté J, Bérubé P, Longpré J-M, Dumaine R, et al. C-Terminal Modifications of Apelin-13 Significantly Change Ligand Binding, Receptor Signaling, and Hypotensive Action. J Med Chem (2015) 58:2431-40. doi: 10.1021/jm501916k

106. Brame AL, Maguire JJ, Yang P, Dyson A, Torella R, Cheriyan J, et al. Design, Characterization, and First-in-Human Study of the Vascular Actions of a Novel Biased Apelin Receptor Agonist. Hypertension (2015) 65:834-40. doi: 10.1161/HYPERTENSIONAHA.114.05099

107. Fischer C, Lamer T, Wang W, McKinnie SMK, Iturrioz X, Llorens-Cortes C, et al. Plasma Kallikrein Cleaves and Inactivates Apelin-17: Palmitoyl- and PEG-Extended Apelin-17 Analogs as Metabolically Stable Blood PressureLowering Agents. Eur J Med Chem (2019) 166:119-24. doi: 10.1016/ j.ejmech.2019.01.040

108. Jia ZQ, Hou L, Leger A, Wu I, Kudej AB, Stefano J, et al. Cardiovascular Effects of a PEGylated Apelin. Peptides (2012) 38:181-8. doi: 10.1016/ j.peptides.2012.09.003

109. Nyimanu D, Kuc RE, Williams TL, Bednarek M, Ambery P, Jermutus L, et al. Apelin-36-[L28A] and Apelin-36-[L28C(30kDa-PEG)] Peptides That 
Improve Diet Induced Obesity Are G Protein Biased Ligands at the Apelin Receptor. Peptides (2019) 121:170139. doi: 10.1016/j.peptides.2019.170139

110. Ason B, Chen Y, Guo Q, Hoagland KM, Chui RW, Fielden M, et al. Cardiovascular Response to Small-Molecule APJ Activation. JCI Insight (2020) 5:132898. doi: 10.1172/jci.insight.132898

111. Gargalovic P, Wong P, Onorato J, Finlay H, Wang T, Yan M, et al. In Vitro and In Vivo Evaluation of a Small-Molecule APJ (Apelin Receptor) Agonist, BMS-986224, as a Potential Treatment for Heart Failure. Circ Heart Fail (2021) 14:e007351. doi: 10.1161/CIRCHEARTFAILURE.120.007351

112. Galon-Tilleman H, Yang H, Bednarek MA, Spurlock SM, Paavola KJ, Ko B, et al. Apelin-36 Modulates Blood Glucose and Body Weight Independently of Canonical APJ Receptor Signaling. J Biol Chem (2017) 292:1925-33. doi: $10.1074 /$ jbc.M116.748103

113. Fischer C, Lamer T, Fernandez K, Gheblawi M, Wang W, Pascoe C, et al. Optimizing PEG-Extended Apelin Analogues as Cardioprotective Drug Leads: Importance of the KFRR Motif and Aromatic Head Group for Improved Physiological Activity. J Med Chem (2020) 63:12073-82. doi: 10.1021/acs.jmedchem.0c01395

114. O'Harte FPM, Parthsarathy V, Hogg C, Flatt PR. Acylated Apelin-13 Amide Analogues Exhibit Enzyme Resistance and Prolonged Insulin Releasing, Glucose Lowering and Anorexic Properties. Biochem Pharmacol (2017) 146:165-73. doi: 10.1016/j.bcp.2017.10.002

115. Juhl C, Els-Heindl S, Schönauer R, Redlich G, Haaf E, Wunder F, et al. Development of Potent and Metabolically Stable APJ Ligands With High Therapeutic Potential. ChemMedChem (2016) 11:2378-84. doi: 10.1002/ cmdc. 201600307

116. Murza A, Sainsily X, Côté J, Bruneau-Cossette L, Besserer-Offroy É, Longpré J-M, et al. Structure-Activity Relationship of Novel Macrocyclic Biased Apelin Receptor Agonists. Org Biomol Chem (2017) 15:449-58. doi: 10.1039/c6ob02247b

117. Trân K, Murza A, Sainsily X, Coquerel D, Côté J, Belleville K, et al. A Systematic Exploration of Macrocyclization in Apelin-13: Impact on Binding, Signaling, Stability, and Cardiovascular Effects. J Med Chem (2018) 61:2266-77. doi: 10.1021/acs.jmedchem.7b01353

118. Miyazaki T, Yamamura Y, Onogawa T, Nakamura S, Kinoshita S, Nakayama S, et al. Therapeutic Effects of Tolvaptan, a Potent, Selective Nonpeptide Vasopressin V2 Receptor Antagonist, in Rats With Acute and Chronic Severe Hyponatremia. Endocrinology (2005) 146:3037-43. doi: 10.1210/en.2004-1590

119. Torres VE, Chapman AB, Devuyst O, Gansevoort RT, Grantham JJ, Higashihara E, et al. Tolvaptan in Patients With Autosomal Dominant Polycystic Kidney Disease. N Engl J Med (2012) 367:2407-18. doi: 10.1056/ NEJMoa1205511

120. Boertien WE, Meijer E, de Jong PE, ter Horst GJ, Renken RJ, van der Jagt EJ, et al. Short-Term Effects of Tolvaptan in Individuals With Autosomal Dominant Polycystic Kidney Disease at Various Levels of Kidney Function. Am J Kidney Dis (2015) 65:833-41. doi: 10.1053/j.jkkd.2014.11.010

121. Tzoulis P, Waung JA, Bagkeris E, Carr H, Khoo B, Cohen M, et al. Real-Life Experience of Tolvaptan Use in the Treatment of Severe Hyponatraemia Due to Syndrome of Inappropriate Antidiuretic Hormone Secretion. Clin Endocrinol (Oxf) (2016) 84:620-6. doi: 10.1111/cen.12943

122. Verbalis JG, Adler S, Schrier RW, Berl T, Zhao Q, Czerwiec FS. Efficacy and Safety of Oral Tolvaptan Therapy in Patients With the Syndrome of Inappropriate Antidiuretic Hormone Secretion. Eur J Endocrinol (2011) 164:725-32. doi: 10.1530/EJE-10-1078

123. Kleinschmidt-DeMasters BK, Norenberg MD. Rapid Correction of Hyponatremia Causes Demyelination: Relation to Central Pontine Myelinolysis. Science (1981) 211:1068-70. doi: 10.1126/science.7466381

124. Wu Y, Beland FA, Chen S, Liu F, Guo L, Fang J-L. Mechanisms of TolvaptanInduced Toxicity in HepG2 Cells. Biochem Pharmacol (2015) 95:324-36. doi: 10.1016/j.bcp.2015.03.015

125. Endo M, Katayama K, Matsuo H, Horiike S, Nomura S, Hayashi A, et al. Role of Liver Transplantation in Tolvaptan-Associated Acute Liver Failure. Kidney Int Rep (2019) 4:1653-7. doi: 10.1016/j.ekir.2019.09.002

126. Feldman BJ, Rosenthal SM, Vargas GA, Fenwick RG, Huang EA, MatsudaAbedini M, et al. Nephrogenic Syndrome of Inappropriate Antidiuresis. N Engl J Med (2005) 352:1884-90. doi: 10.1056/NEJMoa042743

127. Carpentier E, Greenbaum LA, Rochdi D, Abrol R, Goddard WA, Bichet DG, et al. Identification and Characterization of an Activating F229V Substitution in the V2 Vasopressin Receptor in an Infant With NSIAD. J Am Soc Nephrol (2012) 23:1635-40. doi: 10.1681/ASN.2012010077

128. Rochdi MD, Vargas GA, Carpentier E, Oligny-Longpré G, Chen S, Kovoor A, et al. Functional Characterization of Vasopressin Type 2 Receptor Substitutions (R137H/C/L) Leading to Nephrogenic Diabetes Insipidus and Nephrogenic Syndrome of Inappropriate Antidiuresis: Implications for Treatments. Mol Pharmacol (2010) 77:836-45. doi: 10.1124/ mol.109.061804

129. Tiulpakov A, White CW, Abhayawardana RS, See HB, Chan AS, Seeber RM, et al. Mutations of Vasopressin Receptor 2 Including Novel L312S Have Differential Effects on Trafficking. Mol Endocrinol (2016) 30:889-904. doi: 10.1210/me.2016-1002

130. Erdélyi LS, Mann WA, Morris-Rosendahl DJ, Groß U, Nagel M, Várnai P, et al. Mutation in the V2 Vasopressin Receptor Gene, AVPR2, Causes Nephrogenic Syndrome of Inappropriate Diuresis. Kidney Int (2015) 88:1070-8. doi: 10.1038/ki.2015.181

131. Ranieri M, Tamma G, Pellegrino T, Vezzi V, Ambrosio C, Grò C, et al. GainOf-Function Mutations of the V2 Vasopressin Receptor in Nephrogenic Syndrome of Inappropriate Antidiuresis (NSIAD): A Cell-Based Assay to Assess Constitutive Water Reabsorption. Pflugers Arch (2019) 471:1291-304. doi: 10.1007/s00424-019-02307-x

132. Decaux G, Vandergheynst F, Bouko Y, Parma J, Vassart G, Vilain C. Nephrogenic Syndrome of Inappropriate Antidiuresis in Adults: High Phenotypic Variability in Men and Women From a Large Pedigree. J Am Soc Nephrol (2007) 18:606-12. doi: 10.1681/ASN.2006090987

133. Ishida J, Hashimoto T, Hashimoto Y, Nishiwaki S, Iguchi T, Harada S, et al. Regulatory Roles for APJ, a Seven-Transmembrane Receptor Related to Angiotensin-Type 1 Receptor in Blood Pressure in Vivo. J Biol Chem (2004) 279:26274-9. doi: 10.1074/jbc.M404149200

134. Salcedo A, Garijo J, Monge L, Fernández N, Luis García-Villalón A, Sánchez Turrión V, et al. Apelin Effects in Human Splanchnic Arteries. Role of Nitric Oxide and Prostanoids. Regul Pept (2007) 144:50-5. doi: 10.1016/ j.regpep.2007.06.005

135. Katugampola SD, Maguire JJ, Matthewson SR, Davenport AP. [(125)I]-(Pyr(1)) Apelin-13 Is a Novel Radioligand for Localizing the APJ Orphan Receptor in Human and Rat Tissues With Evidence for a Vasoconstrictor Role in Man. $\mathrm{Br} J$ Pharmacol (2001) 132:1255-60. doi: 10.1038/sj.bjp.0703939

136. Hashimoto T, Kihara M, Ishida J, Imai N, Yoshida S, Toya Y, et al. Apelin Stimulates Myosin Light Chain Phosphorylation in Vascular Smooth Muscle Cells. Arterioscler Thromb Vasc Biol (2006) 26:1267-72. doi: 10.1161/ 01.ATV.0000218841.39828.91

137. Pitkin SL, Maguire JJ, Kuc RE, Davenport AP. Modulation of the Apelin/APJ System in Heart Failure and Atherosclerosis in Man. Br J Pharmacol (2010) 160:1785-95. doi: 10.1111/j.1476-5381.2010.00821.x

138. Flahault A, Keck M, Girault-Sotias P-E, Esteoulle L, De Mota N, Bonnet D, et al. LIT01-196, a Metabolically Stable Apelin-17 Analog, Normalizes Blood Pressure in Hypertensive DOCA-Salt Rats via a NO Synthase-Dependent Mechanism. Front Pharmacol (2021) 12:715095. doi: 10.3389/fphar.2021.715095

139. Japp AG, Cruden NL, Amer DAB, Li VKY, Goudie EB, Johnston NR, et al. Vascular Effects of Apelin In Vivo in Man. J Am Coll Cardiol (2008) 52:90813. doi: 10.1016/j.jacc.2008.06.013

140. Szokodi I, Tavi P, Földes G, Voutilainen-Myllylä S, Ilves M, Tokola H, et al. Apelin, the Novel Endogenous Ligand of the Orphan Receptor APJ, Regulates Cardiac Contractility. Circ Res (2002) 91:434-40. doi: 10.1161/ 01.res.0000033522.37861.69

141. Wang C, Du J-F, Wu F, Wang H-C. Apelin Decreases the SR Ca2+ Content But Enhances the Amplitude of [Ca2+]i Transient and Contractions During Twitches in Isolated Rat Cardiac Myocytes. Am J Physiol Heart Circ Physiol (2008) 294:H2540-2546. doi: 10.1152/ajpheart.00046.2008

142. Perjés Á, Skoumal R, Tenhunen O, Kónyi A, Simon M, Horváth IG, et al. Apelin Increases Cardiac Contractility via Protein Kinase Ce- and Extracellular Signal-Regulated Kinase-Dependent Mechanisms. PloS One (2014) 9:e93473. doi: 10.1371/journal.pone.0093473

143. Berry MF, Pirolli TJ, Jayasankar V, Burdick J, Morine KJ, Gardner TJ, et al. Apelin has In Vivo Inotropic Effects on Normal and Failing Hearts. Circulation (2004) 110:II187-193. doi: 10.1161/01.CIR.0000138382.57325.5c

144. Farkasfalvi K, Stagg MA, Coppen SR, Siedlecka U, Lee J, Soppa GK, et al. Direct Effects of Apelin on Cardiomyocyte Contractility and 
Electrophysiology. Biochem Biophys Res Commun (2007) 357:889-95. doi: 10.1016/j.bbrc.2007.04.017

145. Cheng C-C, Weerateerangkul P, Lu Y-Y, Chen Y-C, Lin Y-K, Chen S-A, et al. Apelin Regulates the Electrophysiological Characteristics of Atrial Myocytes. Eur J Clin Invest (2013) 43:34-40. doi: 10.1111/eci.12012

146. Lv W, Zhang L, Cheng X, Wang H, Qin W, Zhou X, et al. Apelin Inhibits Angiotensin II-Induced Atrial Fibrosis and Atrial Fibrillation via TGF- $\beta 1 /$ Smad2/ $\alpha$-SMA Pathway. Front Physiol (2020) 11:583570. doi: 10.3389/ fphys.2020.583570

147. Ashley EA, Powers J, Chen M, Kundu R, Finsterbach T, Caffarelli A, et al. The Endogenous Peptide Apelin Potently Improves Cardiac Contractility and Reduces Cardiac Loading In Vivo. Cardiovasc Res (2005) 65:73-82. doi: 10.1016/j.cardiores.2004.08.018

148. Wang W, McKinnie SMK, Patel VB, Haddad G, Wang Z, Zhabyeyev P, et al. Loss of Apelin Exacerbates Myocardial Infarction Adverse Remodeling and Ischemia-Reperfusion Injury: Therapeutic Potential of Synthetic Apelin Analogues. J Am Heart Assoc (2013) 2:e000249. doi: 10.1161/JAHA.113.000249

149. Azizi Y, Faghihi M, Imani A, Roghani M, Nazari A. Post-Infarct Treatment With [Pyr1]-Apelin-13 Reduces Myocardial Damage Through Reduction of Oxidative Injury and Nitric Oxide Enhancement in the Rat Model of Myocardial Infarction. Peptides (2013) 46:76-82. doi: 10.1016/j.peptides.2013.05.006

150. Li L, Zeng H, Hou X, He X, Chen J-X. Myocardial Injection of ApelinOverexpressing Bone Marrow Cells Improves Cardiac Repair via Upregulation of Sirt3 After Myocardial Infarction. PloS One (2013) 8: e71041. doi: 10.1371/journal.pone.0071041

151. Pchejetski D, Foussal C, Alfarano C, Lairez O, Calise D, Guilbeau-Frugier C, et al. Apelin Prevents Cardiac Fibroblast Activation and Collagen Production Through Inhibition of Sphingosine Kinase 1. Eur Heart J (2012) 33:2360-9. doi: 10.1093/eurheartj/ehr389
152. Barnes GD, Alam S, Carter G, Pedersen CM, Lee KM, Hubbard TJ, et al. Sustained Cardiovascular Actions of APJ Agonism During Renin-Angiotensin System Activation and in Patients With Heart Failure. Circ Heart Fail (2013) 6:482-91. doi: 10.1161/CIRCHEARTFAILURE.11.000077

153. Kuba K, Zhang L, Imai Y, Arab S, Chen M, Maekawa Y, et al. Impaired Heart Contractility in Apelin Gene-Deficient Mice Associated With Aging and Pressure Overload. Circ Res (2007) 101:e32-42. doi: 10.1161/CIRCRESAHA.107.158659

154. Ceylan-Isik AF, Kandadi MR, Xu X, Hua Y, Chicco AJ, Ren J, et al. Apelin Administration Ameliorates High Fat Diet-Induced Cardiac Hypertrophy and Contractile Dysfunction. J Mol Cell Cardiol (2013) 63:4-13. doi: 10.1016/ j.yjmcc.2013.07.002

Conflict of Interest: The authors declare that the research was conducted in the absence of any commercial or financial relationships that could be construed as a potential conflict of interest.

Publisher's Note: All claims expressed in this article are solely those of the authors and do not necessarily represent those of their affiliated organizations, or those of the publisher, the editors and the reviewers. Any product that may be evaluated in this article, or claim that may be made by its manufacturer, is not guaranteed or endorsed by the publisher.

Copyright $\odot 2021$ Girault-Sotias, Gerbier, Flahault, de Mota and Llorens-Cortes. This is an open-access article distributed under the terms of the Creative Commons Attribution License (CC BY). The use, distribution or reproduction in other forums is permitted, provided the original author $(s)$ and the copyright owner(s) are credited and that the original publication in this journal is cited, in accordance with accepted academic practice. No use, distribution or reproduction is permitted which does not comply with these terms. 